\title{
Reliable Flow in Forward and After-sales Supply Chains Considering Propagated Uncertainty
}

\author{
Shabnam Rezapour \\ The Systems Realization Laboratory \\ 202 W. Boyd Street, Room 218 \\ The University of Oklahoma \\ Norman, Oklahoma 73019 USA \\ shabnam.rezapour@ou.edu \\ $+1-216-744-6744$ \\ Janet K. Allen* \\ The Systems Realization Laboratory \\ 202 W. Boyd Street, Room 116-G \\ The University of Oklahoma \\ Norman, Oklahoma 73019 USA \\ janet.allen@ou.edu \\ $+1-405-550-3969$ \\ Farrokh Mistree \\ The Systems Realization Laboratory \\ 865 Asp Avenue, Room 306 \\ The University of Oklahoma \\ Norman, Oklahoma 73019 USA \\ farrokh.mistree@ou.edu \\ +1-405-306-7309
}

*Corresponding author 


\title{
Reliable Flow in Forward and After-sales Supply Chains Considering Propagated Uncertainty
}

\begin{abstract}
An integrated mathematical framework for production planning is presented for companies providing product-warranty packages through both their forward and after-sales supply chains. This model integrates manufacturers and merchandisers of the pre- and after-sales operations and incorporates the interactions between forward and after-sales chains. The demands and qualified output of facilities are stochastic. We demonstrate that service levels depend on the local reliability of facilities and that there are critical prices at which the order of profitability of the warranty options changes. This order becomes more fragile in price-sensitive markets and more stable in warranty-sensitive markets.
\end{abstract}

Keywords: After-sales services; Failure-free warranty; Reliability; Uncertainty propagation; Flow planning in supply chains.

\section{INTRODUCTION}

After-sales service is a marketing strategy used by manufacturers to assure customers of product quality. Hyundai Motor Company changed customer perception about its products by providing an extensive warranty, thus signaling to customers that the quality of its cars had improved (Business Week, 2004). Khajavi et al. (2013) and Baines et al. (2007) believe that in today's markets, the focus of competition has shifted from quality and price to the delivery of value. They believe that customers now value an assurance that the product will work.

Recently, companies have become more aware of the profitability of after-sales service and have started to invest in it further. In high-tech product markets, Lenovo provides after-sales maintenance services for its PC customers (Li et al., 2014). Dell sells its laptops under a default hardware warranty that states “1 Yr Ltd Warranty, 1 Yr Mail-In Service, and 1 Yr Technical Support.” However, customers are offered a 3-year warranty plan for an additional price (dell.com, 2010). In the automobile industry, Nissan offers a 10-year/unlimited mileage warranty for its cars (Nissan, 2011). 
According to Gallagher et al. (2005), providing after-sales service by supplying spare parts for household appliances, automobiles, copy machines, heating and air conditioning is a business worth more than $\$ 200$ billion. In 2009, based on data from the United States Logistics and Material Readiness Office, the US military spent $\$ 194$ billion on their spare parts supply chain (SC) and logistics, with $\$ 104, \$ 70$, and $\$ 20$ billion related to supply, repair, and transportation, respectively. At the end of that year, the value of the spare parts inventory was $\$ 94$ billion. In the automobile industry, retailers of General Motor, Volkswagen and Toyota provide 4S (sale, spare parts, service and survey) services for their customers (Li et al., 2014). Fiat uses TNT Post to handle its distribution of spare parts in Europe and South America. TNT has 2,000 employees and 3 million square feet of warehouse space, handles 120,000 tons of shipments, and processes 34.6 million order lines a year on Fiat's behalf. These numbers illustrate that even a small improvement in the product and its spare parts SCs can lead to a significant gain in profitability.

The after-sales business is an important part of the economy and is nearly twice as profitable as the original product business (Kim et al., 2007). Based on the work of Dennis and Kambil (2003), GM's after-sales revenue of $\$ 9$ billion generated a profit of $\$ 2$ billion. This profit is considerably greater than GM's profit from the $\$ 150$ billion in revenue from its car sales. On average, after-sales services contribute 25 percent of the total revenue but generate more than $40-50$ percent of the total profit.

For these reasons, providing after-sales service is an important part of daily operations in successful companies. These companies have a forward SC and an after-sales SC. Whereas the forward SC involves producing and supplying the original products to the target pre-market, the after-sales SC provides the required spare parts to fulfill the after-sales commitments. Production planning in companies with both forward and after-sales SCs is extremely complex. In addition to having to address two SCs, these chains are not independent. The events occurring in one SC affect the performance of the other chain. Appropriate concurrent flow planning throughout the forward and after-sales SCs is critical to providing good service in the pre- and after-sales markets. Although a company's pre-market service level is typically defined as the product's demand fulfillment rate to avoid lost sales, the after-sales service is a 
function of: i) warranty length and ii) just-in-time fulfillment of the required spare parts inside the warranty period. In the remainder of this paper, the spare parts' demand fulfillment rate is called the aftersales service level. Improving the after-sales service imposes more costs on the after-sales SC but also improves the attractiveness of the product for the customers in the pre-market and stimulates product demand. This is an important interaction between the two SCs. Higher product sales volumes in the premarket augment the spare part or repair requests in the after-sales market. This means that the after-sales demand is a function of the total sales realized in the forward SC. This is another important interaction between the two SCs. These interactions justify the rationality of their concurrent flow planning.

Boone et al. (2008) conducted a Delphi study in 18 industries in which senior service part managers were asked about the challenges in their industries. The main challenge mentioned was "lack of holistic perspective and system integration among SC partners." This result illustrates the strong need to improve integration in after-sales operations. In the academic literature, there is a lack of research with an integrated perspective in the after-sales domain (Bacchetti and Saccani, 2012). According to Boone et al. (2008), McAvoy (2008), Cohen and Agrawal (2006), and Wagner and Lindeman (2008), the main challenges in the after-sales domain are the lack of i) systematic approaches for spare parts management; ii) consideration of SC relationships; iii) accurate models for predicting the demand for spare parts; and iv) practical models for determining appropriate inventory levels. In this paper, we fill the first and second voids by integrating all after-sales operations as an after-sales SC to consider their relationships. Consideration of the interactions between the forward and after-sales SCs significantly improves the after-sales demand prediction, the third deficiency. We also determine the inventory levels of the product and its spare parts to preserve the best pre- and after-sales service levels for the SCs, i.e., the fourth deficiency.

\subsection{Literature on After-sales Services}

In this section, we review some of the work performed in the after-sales literature to highlight the gaps. Detailed information is provided in Table 1. 
For capital goods (Column 2 in Table 1), such as computer networks, and complex technical systems, such as medical or defense systems, the most frequent after-sales services offered by manufacturers are: i) material contracts; ii) performance-based warranties; and iii) end-of-life (EOL) warranties. In these systems, operational disruptions can lead to considerable losses, and the loss becomes greater as the duration of the disruption increases. In material contracts, customers pay the manufacturer for parts, other resources, and labor (Kim et al., 2007). In performance-based warranties (Column 11 in Table 1), there is an agreement with respect to the availability of the system in the field (Chakravarthy and Gómez-Corral, 2009; Chen and Chien, 2007; Chien, 2005; de Smidt-Destombes et al., 2006, 2007, 2009; Finkelstein, 2009; Jhang, 2005; Jung and Park, 2003; Jung and Park, 2003; Kuo and Wan, 2007; Li and Li, 2012; Lieckens et al., 2013; Marseguerra et al., 2005; Nourelfath and Ait-Kadi, 2007; Öner et al., 2010; Sahba and Balc1og lu, 2011; Wang et al., 2009; Yeh et al., 2005). EOL warranties (Column 10 in Table 1) ensure after-sales service without a time limit. The company provides the required service as long as the products are in use, even if their production has been discontinued (Kim and Park, 2008).

For durable consumer goods (Column 3 in Table 1), which are considered in this paper, rebate warranties and failure-free warranties are the most common after-sales policies. Rebate warranties (Column 8 in Table 1) are typically used for non-repairable goods, and manufacturers commit to refund customers some portion of the sale price if the product fails during the warranty period. Goods such as automobile batteries and tires are typically sold with this type of warranty. Failure-free warranties (Column 9 in Table 1) are commonly used for household appliances and electronic devices, and with these warranties, manufacturers commit to repair products free of charge during the warranty period. As highlighted by Cohen and Agrawal (2006), Niemi et al. (2009), and Wagner and Liedermann (2008), little work has been completed on warranty service and spare parts management for failure-free warranties. See Bacchetti and Saccani (2012) for a review of the literature of spare parts classifications and demand prediction for stock control. According to Kleber et al. (2011), the focus of the majority of the work performed in spare parts management has been only on inventory management (Columns 18-27 and 30 in Table 1). For example, Chien and Chen (2008) have developed a model for optimal spare parts ordering 
for a non-repairable product under a rebate warranty. They assume that the lead times to fulfill the orders are stochastic and follow a given probability distribution. They determine the ordering policy to maximize profit, which is expressed as the difference between rebate gains and the total cost, including ordering, storage, and holding expenses. These papers overlook the manufacturing systems supporting the inventory systems and the flow transactions that exist between these two portions.

A great deal of the after-sales work focuses on the marketing aspect of after-sales services, such as investigating the trade-off between the repair/replacement cost and the income without incorporating the SC supporting its operations (Chen et al., 2012; Chu and Chintagunta, 2009; Esmaeili et al., 2014; Jung et al., 2015; Kurata and Nam, 2010; Kurata and Nam, 2013; Li et al., 2012; Li et al., 2014; Majid et al., 2012; Su and Shen, 2012; Wei et al., 2015; Zhou et al., 2009). For example, Zhou et al. (2009) have developed a model to dynamically determine the best price and warranty for a product in its lifecycle by considering the purchase pattern of customers. Chen et al. (2012) investigate pricing strategies for a company with two competing retailers servicing markets with warranty-dependent demands. Kurata and Nam (2010 and 2013) explore the interaction of basic and optional after-sales services for durable consumer products. Esmaeili et al. (2014) have determined the optimal sale price, warranty period, and warranty price for a manufacturer under three-level service contacts (Columns 13-16 and 28 in Table 1 correspond to these decisions). These papers only concentrate on the downstream marketing effects of after-sales services. They overlook the upstream manufacturing operations in the SCs that support these marketing strategies. In this paper, upstream manufacturing operations are included in our problem by considering the forward and after-sales SCs that back up the marketing strategies in the pre- and aftersales markets.

Recently, various researchers have considered the engineering aspects of after-sales services in addition to their marketing aspects, e.g., making decisions about the reliability of the product (Chen and Chu, 2001; Huang et al., 2007; Hussain and Murthy, 2003; Kamrad et al., 2005; Lin and Shue, 2005; Öner et al., 2010; Sheu and Chien, 2005; Wu et al., 2006). Columns 17 and 29 in Table 1 correspond to these decisions. For example, Huang et al. (2007) have proposed a model for simultaneously determining 
product reliability, retail price, and warranty for a repairable product sold with a free replacement-repair warranty to maximize the total achievable profit. They assume that the product sales rate is an increasing function of warranty length and a decreasing function of retail price. Öner et al. (2010) have developed a model to support a manufacturer that designs and supplies a system to its customers through a service contract. This model selects the best reliability level for a critical component of the system. These papers only concentrate on the design and marketing aspects of the supplied products and ignore their manufacturing processes. We incorporate the manufacturing process into our problem by considering the SCs of the product and its spare parts.

This review illustrates that the literature has largely ignored the manufacturing facilities supporting after-sales services and the integration between these facilities. This has led to a lack of holistic integration and a lack of comprehensive planning in the facilities supporting these services. In this paper, we fill this gap by considering the after-sales SC including all facilities supporting the after-sales services. We consider not only the interactions of facilities inside the after-sales SC but also the interactions of this chain with the forward SC. To the best of our knowledge, these interactions are ignored in the literature (Columns 6 and 7 in Table 1). To fill these gaps, we answer the following question in this paper:

What is the most profitable integrated production plan for companies having both forward and after-sales SCs to service pre- and after-sales markets?

This paper considers a company that produces and supplies a durable consumer product to a target market through its forward SC. These products are sold with a warranty that states that all of the product's failures will be repaired free of charge. The spare parts required to repair the returned products are produced and supplied through the after-sales SC. We develop a mathematical model to concurrently determine the most profitable production plan in the forward and after-sales SCs. Flow transactions between facilities involving marketing and production operations and interactions between the forward and after-sales SCs are considered in this model. In the next section, we explain the uncertainties considered in this integrated production plan model. 


\subsection{Literature Related to Uncertainty in Supply Chains}

We consider two groups of uncertainties in the flow planning of the SCs: i) demand-side uncertainties, including the uncertainty in the product and after-sales service demand; and ii) supply-side uncertainties related to the imperfect production systems of the SCs' production facilities.

Although there is a large body of work that considers uncertainty in the product demand of the premarkets (Baghalian et al., 2013; Cardona-Valdés et al., 2011; Daniel and Rajendran, 2006; Hsu and Li, 2011; Ko and Evans, 2007; Mohammaddust et al., 2015; Pan and Nagi, 2010; Park et al., 2010; Rezapour et al., 2013; Rezapour et al., 2014a, 2014b; Rezapour et al., 2015a, 2015b; Rezapour and Farahani, 2014; Romeijn et al., 2007; Schütz et al., 2009; Shen and Qi, 2007; You and Grossmann, 2008) and the repair demand of the after-sales markets (Faridimehr and Niaki, 2012; Kurata and Nam, 2010; Lin and Shue, 2005; Rappold and Van Roo, 2009; van Ommeren et al., 2006; Wang et al., 2009; Wang, 2012; Wu et al., 2009), uncertainty in the performance of the production systems in the SCs' facilities is often ignored (Column 33 in Table 1).

In the literature, it is mainly assumed that SCs' production facilities are perfect and only have conforming output (Rezapour et al., 2015a, 2015b). However, in reality, there is no perfect production system. Due to machinery and labor failures, production systems always have some stochastic proportion of nonconforming output (Sana, 2010). We fill this gap of the literature by determining the best pre- and after-sales service levels in the presence of both demand- and supply-side uncertainties. To fill this gap, we answer the following question in this paper:

What are the best service levels in the pre-and after-sales markets in the presence of demand-and supply-side uncertainties?

Consideration of supply-side uncertainties is critical for service-level estimation in SCs. The service level indicates the capability of a SC to balance supply and demand. Therefore, consideration of possible variations in a SC's qualified supply quantity significantly improves the accuracy of its service level estimation. In this paper, we aim to determine the best service level for the forward and after-sales SCs in 
the presence of demand- and supply-side uncertainties. We demonstrate that in SCs with several stochastic production facilities, qualified flow depreciates when moving from upstream to downstream, which adversely affects its service level. To neutralize the negative effects of flow depreciation, we develop an approach that amplifies the orders among the SCs' facilities from downstream to upstream. Therefore, the development of a reliable flow in the forward and after-sales SCs against flow depreciation to preserve the pre- and after-sales service levels is the other contribution of this problem.

Detailed information of various relevant works is summarized in Table 1. The "Good" column of the table indicates the type of the investigated good: capital or consuming. The "Operation" column indicates whether the pre- or after-sales market operations (or both) are considered. The "Warranty" column indicates the good's warranty type: rebate, failure-free, EOL, or performance-based. The "Output" column indicates the decisions determined by the models of the papers. The objective functions and constraints of the models are listed in the "Objective" and "Constraint" columns, respectively. The stochastic parts of the models are summarized in the "Uncertainty" column of the table.

\subsection{Contributions of the Paper}

In this paper, we propose an integrated mathematical model for coordinating all of the facilities involved in the complex production system of manufacturing companies that provide a product/after-sales service package for their customers. The contributions of this work are as follows:

$\checkmark$ After-sales servitization: In addition to downstream marketing effects of the after-sales services, we also incorporate their supporting upstream manufacturing operations in our model. Integration of after-sales providers and merchandiser facilities fills the "lack of system integration" gap noted in the literature review (the flow transactions between these facilities are explained in Section 2 and quantified in Section 3.2);

$\checkmark$ Integration of forward and after-sales SCs: The operations of the forward and after-sales SCs are typically planned separately in the literature (see Columns 6-7 in Table 1). In this paper, we determine the important interactions that exist between these two SCs and justify the necessity of 
their concurrent flow planning. Incorporating these interactions not only improves demand and required inventory predictions in pre- and after-sales markets but also strengthens the holistic perspective and system integration in product/after-sales service provider companies (the interactions between the SCs are explained in Section 2, quantified in Sections 3.1 and 3.2, and incorporated in the integrated mathematical model developed in Section 3.3);

$\checkmark$ Managing supply-side uncertainties in SCs: In the literature, the performances of production facilities in SCs are assumed to be perfect (see Column 33 in Table 1). In this paper, we relax this assumption by considering that inherent uncertainties exist in the imperfect production systems of the practical world. We demonstrate that in SCs with imperfect facilities, qualified and presentable flow depreciates when moving from upstream to downstream. Flow depreciation adversely affects service levels in markets. We suggest that amplifying orders from the downstream to the upstream of the SCs neutralizes flow depreciation and helps to preserve the desired service levels in pre- and after-sales markets (neutralizing flow depreciation in the forward and after-sales SCs is explained in Sections 3.1 and 3.2, respectively).

The remainder of this paper is organized as follows. The problem definition is presented in Section 2. The problem is modeled in Section 3. After a discussion of the model's specific characteristics, a solution method is proposed in Section 4. The model and its solution approach are used to solve a sample problem in Section 5. The computational results reveal correlations among the company's marketing strategies. Closing remarks are given in Section 6.

\section{TABLE 1 goes about here}

\section{PROBLEM DEFINITION}

This problem considers a company producing and supplying a durable product to a target market. The production and distribution processes of this product are implemented in the facilities of the forward SC. This product includes $r$ critical components manufactured in suppliers of the first echelon. The 
components are transported to a manufacturer in the second echelon, and after assembly, the final product is supplied to the final customers through a retailer (Figure 1). The products of each sale period are produced, transported and stored in the SC's retailer before the beginning of that period.

Figure 1 goes about here.

The product demand is stochastic and depends on the product's price, its availability in the pre-market (called the pre-market service level), the spare parts' availability after-sales (called the after-sales service level), and the warranty length. Whenever a product is sold, a failure-free warranty is provided, which is implementable from the time of sale. Any failure in the product, which is mainly caused by the failure of its key components, is repaired without charge within this warranty period. Without loss of generality, it is assumed that typically, the first $n_{i}(i=1,2, \ldots, r)$ failures of these components are repaired but that failed components are substituted with new components stored by the retailer.

The components required to provide after-sales services for customers are produced and supplied by the company's after-sales SC. The components required to fulfill the after-sales commitments of each sales period are produced by the suppliers and directly transported to the retailer and stored there before the beginning of that period (Figure 2). Accurate prediction of the required components is an important element of this problem and plays a key role in preserving the recommended after-sales service level.

\section{Figure 2. Goes about here}

Two important interactions between these two SCs are: 1) the dependence of the demand of the forward SC in the pre-market on the service level provided by the after-sales SC; and 2) the dependence of the after-sales demand of the components on the total products supplied by the forward SC to the market and the quality of the product's components. These interactions are incorporated in the concurrent flow planning of these two SCs.

We consider several different sources of uncertainty in this problem. 1) Demand-side uncertainty: there are several sources of demand-side uncertainty in this problem. The first uncertainty is related to the 
product's demand in the pre-market. The pre-market's demand is assumed to be a stochastic function of price, warranty length and service levels in the pre- and after-sales markets. The after-sales demands for spare parts are functions of the quantity of product sales in the pre-market and the quality of the product's components. Both of these factors are nondeterministic. We assume that the failure times of the product's components are stochastic and follow given density functions depending on their reliability parameters. 2) Supply-side uncertainty: to make the problem more compatible with actual conditions, it is assumed that the production systems of the SCs' facilities are not perfect and that their output always has a stochastic percentage of nonconforming production. In our problem, the performance of the suppliers and the manufacturer includes a stochastic percentage of nonconforming output.

In a company with these specifications, it is important to make the following decisions to maximize the total profit: 1) the best marketing strategy for this company (price, warranty length, and, service levels); and 2) the best reliable flow dynamics throughout the SCs, preserving the service levels in the pre- and after-sales markets.

\section{MATHEMATICAL MODEL OF THE PROBLEM}

The problem here includes two distinct but highly interconnected parts: the forward SC and the after-sales SC. There are several interactions between the forward and after-sales SCs. For example, the total product sales in the forward SC determine the potential demand for the spare parts in the after-sales market. Additionally, the after-sales services provided by the after-sales SC, such as warranty and spare parts availability, play an important role in the forward SC's captured demand in the pre-market. Therefore, there is synergy in the simultaneous flow planning of the forward and after-sales SCs.

In the remainder of this section, we first address planning flow dynamics through the forward SC with stochastic facilities and then shift to the after-sales SC. Thereafter, a comprehensive mathematical model that yields the most profitable marketing strategies (price, warranty, and service levels) and preserves the flow plan for the company under consideration is proposed by considering the interactions between these 
two SCs. The solution of this model includes the synergy of concurrent coordination compared to a hierarchical decision-making process that is easier but leads to sub-optimal solutions for this problem.

The notations used in this paper are summarized in Table 2.

\section{Table 2 goes about here.}

\subsection{Forward Supply Chain Formulation}

In this section, only decisions related to the flow dynamics in the forward SC will be considered. As noted above, there are several sources of uncertainty in the forward SC: i) uncertainty in the product demand in the pre-market; and ii) uncertainty in the performance of the manufacturer's and suppliers' production systems. In the remainder of this section, all of the forward SC's facilities are sequentially investigated from downstream to upstream, and a procedure for reliable flow planning is implemented in each facility against its corresponding uncertainty. In addition to investigating the local effects of these uncertainties, we also investigate their global effects on the performance of the entire forward SC.

As shown in Figure 3, the forward SC considered here has three echelons, and the facilities in each echelon are faced with various uncertainties. The retailer of the first echelon faces uncertain market demand, which has a given distribution function. The production system of the manufacturer in the second echelon is always accompanied with some stochastic waste. After setup, the production processes of the suppliers in the third echelon start their machinery in a state of control. However, the state of the machinery deteriorates and shifts to an out-of-control state after a stochastic amount of time, which leads to a stochastic percentage of nonconforming output. Due to the imperfect production systems of the suppliers, the precise volume of their qualified component output for a given material input quantity cannot be determined. Thus, the qualified output volumes can change and are stochastic. The output components of the suppliers are the input for the manufacturer. Uncertainty in the input volume of the manufacturer is amplified because of the stochastic wastage ratio for the manufacturer's production system, which leads to a higher uncertainty in the qualified product output of the manufacturer. This

process continues by moving material, components, and product from upstream to downstream in multi- 
echelon SCs with imperfect facilities. We call this phenomenon "uncertainty propagation," which leads to the qualified flow depreciation throughout the SCs' networks (see Figure 3).

Determining the optimal service level is more difficult in such a SC due to the flow depreciation that occurs by moving the flow from upstream to downstream. In such a network with multiple stochastic facilities, a local reliability is assigned to each facility to manage the uncertainty of its own system. It is assumed that $r l_{1}, r l_{2}$, and $r l_{3}$ represent the local reliability in the retailer, manufacturer, and suppliers of the SC, respectively (without loss of generality, we consider similar reliabilities for the suppliers; the same logic can be applied for different reliabilities).

In this problem, we exploit the newsboy problem style to manage the inventory system of the retailer. Based on this system, products should be procured and stocked by the retailer before the beginning of each sales period and by realizing its actual demand because transferring additional products between the manufacturer and retailer is not possible during the period. Thus, $r l_{1}$, the local reliability of the retailer, suggests that before the beginning of the next sale period, the retailer must select its product stock quantity to ensure with $r l_{1}$ probability that this stock level can respond to the market demand. The retailer orders the required products from the manufacturer. Furthermore, the local reliability of the manufacturer, $\mathrm{rl}_{2}$, means that the manufacturer must manufacture an appropriate product quantity to guarantee that the qualified output is equal to the order of the retailer with a probability of $r l_{2}$. The local reliability of each supplier, $r l_{3}$, means that the material procurement and component production quantity should preserve the order of the manufacturer with a probability of $r l_{3}$. We assume that each facility either completely fulfills the order of its downstream facility and sends a complete package equal to its order, or misses the order and sends nothing. Flow transactions less than orders is not possible among facilities. In this case, the suppliers will be confident with a probability of $r l_{3}{ }^{r}$ that they can fulfill the manufacturer's component orders. The manufacturer will be confident with a probability of $r l_{2}$ that it is able to provide the complete order of the retailer, and the retailer will be confident with a probability of $r l_{1}$ that its product stock quantity can fulfill the demand of the market. Therefore, the final service level of the 
forward SC in the pre-market is $s l_{p}=r l_{1} \times l_{2} \times\left(r l_{3}\right)^{r}$. In this problem, in addition to determining the optimal $s l_{p}$, but it is also essential to determine the optimal local reliability combination $\left(r l_{1}, r l_{2}, r l_{3}\right)$ that preserves that service level.

\subsubsection{Retailer in the forward SC}

The company positions itself in the market by choosing its service levels in the pre- and after-sales markets, its warranty time, and its retail price. The expected product demand in the pre-market $D\left(p, s l_{p}, s l_{a}, w\right)$ in the sales period $T$ is an increasing function of the chains' service levels and warranty time and a decreasing function of the product's price. However, the actual demand is a stochastic function and deviates from its mean value. It is assumed that the stochastic demand function of the pre-market has a multiplicative form: $\bar{D}\left(p, s l_{p}, s l_{\alpha}, w\right)=D\left(p, s l_{p}, s l_{\alpha}, w\right) \times \varepsilon$ (Bernstein and Federgruen, 2004, 2007), where $\varepsilon$ is a general continuous random variable with a stationary distribution function and a cumulative distribution function, $G(\varepsilon)$, which are independent of the service levels, warranty time, and price. Without loss of generality, $E(\varepsilon)=1$ is normalized, which implies that $E\left[\bar{D}\left(p, s l_{p}, s l_{a}, w\right)\right]=D\left(p, s l_{p}, s l_{a}, w\right)$.

\section{Figure 3 goes about here}

Companies typically provide the price $(p)$ and warranty $(w)$ information of products to customers directly. However, there are several channels through which customers can acquire information about preand after-sales services provided by companies indirectly. There are thousands of independent Internet websites t.hat review products and provide useful information about the pre- and after-sales performance of companies, such as their service level warranties, spare parts availability, and back-up chargeback agreements (e.g., ConsumerReports.org, Epinions.com). This information helps customers make informed decisions and affects the average demand. Recently, most companies have started to advertise their service levels. For example, Sunning and Gome, the largest and second-largest suppliers of home electronic appliances in China, respectively, recently started to advertise their after-sales service level commitments to compete for customers. Both are selling similar models of air conditioners at the same 
price. To stimulate demand, both offer to clean sold air conditioners at least once a year. However, to dominate their rival, Gome has started to commit to a response time of no more than 72 hours for a customer's request for an air conditioner cleaning. As another example, most automobile manufacturers, such as BMW, Volkswagen, and Ford, prominently state the average waiting time for car maintenance per customer in their $4 \mathrm{~S}$ retailers. They also employ third-party agencies to monitor the service level provided by their retailers (Li et al., 2014). These examples illustrate that not only providing better after-sales services, such as longer warranty length, but also the quality of the service provided inside the commitment period, such as a higher service level and shorter waiting time, are important for customers in competitive markets. Therefore, we assume that 1) the warranty length, $w$, and after-sales service level, $s l_{a}$, are two mutually independent factors with different importance affecting customer purchasing decisions and the captured demand of the company; and 2) customers are informed of the after-sales service level commitment when they make a purchasing decision (Allon and Federgruen, 2009; Li et al., 2014).

The effect of the second assumption can be mitigated by substituting the $\theta \times s l_{a}$ term instead of $s l_{a}$ in the $D\left(p, s l_{p,} s l_{\infty}, w\right)$ function $(0 \leq \theta \leq 1)$. $\theta$ represents the level of information availability about the after-sales service level commitment $(\theta=0$ means that no information is available, and $\theta=1$ means that complete information is available to customers).

In this section, we only focus on the operation of the forward SC. Therefore, the pre-market's service level is the focus here. The pre-market's service level is defined as the fraction of the pre-market's realized product demand that can be satisfied from the on-hand product inventory available in the retailer (Rezapour, 2011). The retailer must order the product stock, $x$, from the manufacturer before the beginning of the sale period. By realizing the period's real product demand, the unit holding cost, $h^{+}$, and unit shortage cost, $h^{-}$, are paid by the retailer for each end-of-period additional inventory and lost sale, respectively. The expected value of the retailer's cost, $\Pi$, is computed with Equation (1). Constraint (2) 
preserves the retailer's local reliability, which guarantees that the retailer's product stock can fulfill the pre-market's product demand for $r l_{1}$ percent of cases. Thus, the product order quantity of the retailer from the manufacturer can be computed as

$$
\begin{array}{ll}
\text { MIN } & \mathbb{C}=h^{+} \cdot E\left[x-\widehat{D}\left(p, s l_{p}, s l_{a}, w\right)\right]^{\top}+h^{-} \cdot E\left[\widehat{D}\left(p, s l_{p,} s l_{a}, w\right)-x\right]^{\top} \\
\text { S.T. } & \operatorname{Pr}\left[\bar{D}\left(p, s l_{p}, s l_{a}, w\right) \leq x\right] \geq r l_{1}
\end{array}
$$

Based on the objective function, $x=D\left(p, s l_{p}, s l_{\alpha}, w\right) \cdot G^{-1}\left(\frac{h^{-}}{h^{-}+h^{+}}\right)$minimizes the expected cost of the retailer, and to preserve the constraint, $x \geq D\left(p, s l_{p}, s l_{a}, w\right) \cdot G^{-1}\left(r l_{1}\right)$. Accordingly, the best product ordering amount of the retailer from the manufacturer is

$x=D\left(p, s l_{p}, s l_{a}, w\right) \cdot G^{-1}\left(\operatorname{Max}\left\{r l_{1}, \frac{h^{-}}{h^{-}+h^{+}}\right\}\right)$

By substituting Equation (3) into (1), the lowest total cost of the retailer can be calculated as

$$
\mathbb{C}=\left(h^{+} \cdot E\left[G^{-1}\left(\operatorname{Max}\left\{r l_{1}, \frac{h^{-}}{h^{-}+h^{+}}\right\}\right)-\varepsilon\right]^{+}+h^{-} \cdot E\left[\varepsilon-G^{-1}\left(\operatorname{Max}\left\{r l_{1}, \frac{h^{-}}{h^{-}+h^{+}}\right\}\right)\right]^{+}\right) \cdot D\left(p, s l_{p}, s l_{a}, w\right)
$$

When the retailer orders $x$ product units from the manufacturer, this protects the pre-market's product demand such that it can be fulfilled from the retailer's on-hand product inventory with a probability of $r l_{1}$ (see the retailer in Figure 3). Section 3.1.2 illustrates how this product's flow quantity must be amplified by moving backward to the manufacturer in the forward SC.

\subsubsection{Manufacturer in the forward SC}

The forward SC's manufacturer receives an order of $x$ product units from the retailer and then orders the required components from the suppliers. Without loss of generality, it is assumed that one unit of each component is required to produce one unit of product. However, the production system of the manufacturer is always accompanied by some wastage. The ratio of wastage to qualified product depends on the general state of its machinery, which varies from time to time. It is assumed that the wastage ratio 
of the manufacturer's output changes over the range $[0, \beta]$ with a cumulative distribution function $G^{\prime}($.$) .$

The manufacturer attempts to compensate for this wastage in its production system by manufacturing additional product and consequently orders additional components from the suppliers.

If the manufacturer produces $x$ product units, this production lot contains less than $\Delta x=\alpha \cdot x(\alpha \in[0, \beta])$ flawed product units with $G^{\prime}(\alpha)$ probability. Therefore, the manufacturer plans to produce $\Delta x+x$ product units to be confident with a probability of $G^{\prime}(\alpha)$ that the entire order of the retailer is fulfilled. Because the local reliability of the manufacturer is assumed to be $r l_{2}\left(=G^{\prime}(\alpha)\right)$, the additional production quantity of the manufacturer is $\Delta x=\tilde{G}^{-1}\left(r l_{2}\right) \cdot x$. Thus, the manufacturer should order $\Delta x+x$ component units from each supplier in the forward SC. As noted above, the manufacturer only fulfills the $x$ product order of the retailer before the beginning of the next period, and additional product acquisition during the next sales period is impossible.

Producing $\Delta x+x$ product units by the manufacturer ensures that it can fulfill the $x$ product order of the retailer with a probability of $r l_{2}$ (see the manufacturer in Figure 3). Section 3.1.3 provides a discussion of how these component flow quantities are amplified by moving backward to the suppliers of the forward SC.

\subsubsection{Suppliers in the forward $S C$}

Each supplier receives an order of $\Delta x+x$ component units from the retailer. After setting up the system, the production run starts in an in-control state of Supplier $i$ 's machinery $(i=1,2, \ldots, r)$. However, the machinery state deteriorates and shifts to an out-of-control state after a period of time. The time for deterioration is stochastic and has an approximately exponential distribution with mean $1 / \mu_{i}$ (Lee and Rosenblatt, 1987; Rosenblatt and Lee, 1986). All of the component units produced in the in-control state are qualified, but from the units produced in the out-of-control state, $\gamma_{i}$ percent are defective. Once the process shifts to the out-of-control state, it stays in this state until the entire production batch is finished because interrupting the machinery is either impossible or too expensive. 
Each supplier should produce $\Delta x+x$ flawless component units. To compensate for the flawed component production in its production system, the supplier should plan to produce more components, $\Delta \dot{x}_{i}+\Delta x+x$. The additional quantity of units, $\Delta \dot{x}_{i}$, is added to the production system of Supplier $i$ to replace the defective component units. If it is assumed that the production rate of Supplier $i$ is $P R_{1 i}$, it takes $\frac{\Delta x_{i}+\Delta x+x}{P R_{1 i}}$ time units to produce this component volume. The additional volume $\Delta \hat{x}_{i}$ should be determined in such a manner to preserve the local reliability of the supplier, $r l_{3}$ :

$$
\begin{aligned}
r l_{3} & =\operatorname{Pr}\left(\text { flawless component units produced in } \frac{\Delta \hat{x}_{i}+\Delta x+x}{P R_{1 i}} \text { time units } \geq \Delta x+x\right) \\
& =\operatorname{Pr}\left[P R_{1 i} \cdot t+\left(1-\gamma_{i}\right) \cdot P R_{1 i} \cdot\left(\frac{\Delta x_{i}+\Delta x+x}{P R_{1 i}}-t\right) \geq \Delta x+x\right]=\operatorname{Pr}\left[t \geq\left(\frac{\Delta x+x}{P R_{1 i}}\right)-\left(\frac{1-\gamma_{i}}{\gamma_{i} \cdot P R_{1 i}}\right) \cdot\left(\Delta \dot{x}_{i}\right)\right] \\
& =E X P\left[-\mu_{i i} \cdot\left(\left(\frac{\Delta x+x}{P R_{1 i}}\right)-\left(\frac{1-\gamma_{i}}{\gamma_{i} \cdot P R_{1 i}}\right) \cdot\left(\Delta \dot{x}_{i}\right)\right)\right]
\end{aligned}
$$

Based on the equation above, $\Delta \dot{x}_{i}=\frac{\gamma_{i}}{1-\gamma_{i}}\left[\frac{P R_{1 i}}{\mu_{i}^{i}} \ln \left(r l_{3}\right)+(\Delta x+x)\right]$ units of additional component production for Supplier $i$ ensures the local reliability for that supplier with a probability of $r l_{3}$. This means that with this amount, $\Delta \hat{x}_{i}$, the supplier is able to fulfill the order of the manufacturer $r l_{3}$ percent of the time and preserve the local reliability $r l_{3}$ for itself (see the suppliers in Figure 3). Therefore, with these values of $\Delta \hat{x}_{i}(i=1,2, \ldots, r)$, the suppliers are able to fulfill the orders of the manufacturer with a probability of $\mathrm{rl}_{3}{ }^{r}$. With the amount of $\Delta x$ determined in Section 3.1.2, the manufacturer is able to fulfill the product order of the retailer with a probability of $r l_{2}$. With a product volume of $x$, the retailer is able to respond to the realized product demand of the pre-market with a probability of $r l_{1}$. Thus, supplier production volumes of $\Delta \hat{x}_{i}+\Delta x+x(i=1,2, \ldots, r)$ are able to fulfill the product demand in the premarket with a probability of $r l_{1}, r l_{2}, r l_{3}{ }^{r}$ and preserve the service level $s l_{p}=r l_{1}, r l_{2}, r l_{3}{ }^{r}$ for the entire forward chain against uncertainty propagation in its entities (Figure 3). 


\subsection{After-sales Supply Chain Formulation}

This section considers the flow planning decisions in the after-sales SC. The after-sales SC has several uncertainties: i) uncertainty in the demand for spare parts in the retailer to repair or substitute failed components of returned products; and ii) uncertainty in the performance of the production systems in the suppliers. In the remainder of this section, the performance of the after-sales SC's facilities is formulated sequentially from the retailer in the downstream to the suppliers in the upstream. Here, flow planning in the after-sales SC is determined, which will not only locally assure appropriate reliabilities for the chain's facilities against their uncertainties but also yield an acceptable performance for the entire after-sales SC.

\subsubsection{Retailer in the after-sales $S C$}

Based on Section 3.1, if it is assumed that $r l_{1}$ and $r l_{3}$ represent the local reliabilities in the retailer and suppliers, respectively, then the service levels provided by the forward and after-sales SCs are $s l_{p}=r l_{1}, r l_{2}, r l_{3}{ }^{r}$ and $s l_{a}=\left(r l_{1} \cdot r l_{3}\right)^{r}$, respectively. Similar to the forward SC, in the after-sales SC, the first after-sales operation starts in the retailer. Uncertainty in the after-sales SC's retailer is related to the demand for spare parts. The demand for spare parts in the retailer is caused by the failed components in returned products that require part substitution. Thus, the demand for spare parts in the after-sales market is a function of the total product sales in the pre-market and the reliability of the product's key components. Then, for a given product sales in the pre-market, $x$, and a given component reliability, $\lambda_{i}$ $(i=1,2, \ldots, r)$, it is necessary to find an appropriate density function for the demand of the component.

The performances of the components in the product are assumed to be independent. The failure time of Component $i$ has a density function $f_{i}$ and cumulative density function $F_{i}$, including the reliability parameter $\lambda_{i}(i=1,2, \ldots, r)$. Lower values of the parameter $\lambda_{i}$ imply a higher reliability and lower failure of Component $i$. It is typically assumed that for each product, the retailer must repair the first $n_{i}$ failures of Component $i$ with repair $\operatorname{cost} c n_{i}$, but after that, the failed component is replaced with a new one. $n_{i}=0$ 
implies a non-repairable component in the product. We also assume that the breakdown probability of a failed component does not change after repair and that the time required for the repair or substitution of components is negligible compared to the warranty time, $w$ (Nguyen and Murthy, 1984).

If $F_{i}^{(m)}$ is defined as the cumulative density function of the total time to the $m^{\text {th }}$ failure and $\operatorname{Num}_{i}(w)$ represents the random number of failures in $[0, w]$, then we have (Nguyen and Murthy, 1984)

$$
\operatorname{Pr}\left\{\operatorname{Num}_{i}(w)=m\right\}=F_{i}^{(m)}\left(w, \lambda_{i}\right)-F_{i}^{(m+1)}\left(w, \lambda_{i}\right) \quad(\forall i=1,2, \ldots, r)
$$

The following can be stated based on Equation 6:

Lemma 1: The average number of Component $i$ substitutions, $E_{i}\left(w, n_{i}\right)$, for a product unit is calculated as follows (see the proof in Appendix A):

$$
E_{i}\left(w, n_{i}\right)=\left(n_{i}\right) F_{i}^{\left(n_{i}+1\right)}\left(w, \lambda_{i}\right)+\sum_{j=n_{i}+1}^{+\infty} F_{i}^{(j)}\left(w, \lambda_{i}\right) \quad(\forall i=1,2, \ldots, r)
$$

Lemma 2: The variance in the number of Component $i$ substitutions, $\sigma_{i}^{2}\left(w, n_{i}\right)$, for a product unit is calculated as follows (see the proof in Appendix A):

$$
\begin{gathered}
\sigma_{i}^{2}\left(w, n_{i}\right)= \\
\quad\left(n_{i}+1\right)^{2} F_{i}^{\left(n_{i}+1\right)}\left(w, \lambda_{i}\right)+\sum_{j=n_{i}+2}^{+\infty}[2 j-1] \cdot F_{i}^{(j)}\left(w, \lambda_{i}\right)-\left[\left(n_{i}\right) F_{i}^{\left(n_{i}+1\right)}\left(w, \lambda_{i}\right)+\right. \\
\left.\sum_{j=n_{i}+1}^{+\infty} F_{i}^{(j)}\left(w, \lambda_{i}\right)\right]^{2} \\
\quad(\forall i=1,2, \ldots, r)
\end{gathered}
$$

Now, the total number of required Component $i$ substitutions for a lot size of $x$ product units can be estimated to represent the demand for Component $i$ in the after-sales market, $D_{i}$. $D_{i}$ is the sum of required Component $i$ substitutions for $x$ individual units. Because $x$ is large, the following can be stated based on the central limit theorem:

Lemma 3: The demand of Component $i$ in the after-sales market, $D_{i}$, can be approximated as being normally distributed with a mean of $x, E_{i}\left(w, n_{i}\right)$ and variance of $x \cdot \sigma_{i}^{2}\left(w, n_{i}\right)$ : 


$$
D_{i} \sim \operatorname{Normal}\left(\mu_{D_{i}}=x . E_{i}\left(w, n_{i}\right), \sigma_{D_{i}^{i}}^{2}=x . \sigma_{i}^{2}\left(w, n_{i}\right)\right) \quad(\forall i=1,2, \ldots, r)
$$

Thus, the after-sales SC is faced with a normally distributed random demand for components. Because a local reliability of $r l_{1}$ is assumed for the retailer, the stock quantity of Component $i$ that preserves this local reliability in the retailer is

$$
x_{i}=x \cdot E_{i}\left(w, n_{i}\right)+\left(z_{r l_{1}} \cdot \sqrt{x, \sigma_{i}^{2}\left(w, n_{i}\right)}\right) \quad(\forall i=1,2, \ldots, r)
$$

We assume that the retailer provides the same reliability for both forward and after-sales SCs. The problem would be simplified by assigning different reliabilities for the retailer because in that case, the service levels of the forward and after-sales SCs are independent.

Assuming that the first $n_{i}$ failures of Component $i$ in each product are repaired by the retailer with a repair cost $c n_{i}$, the average repair cost of the product at the retailer is

$c r=\sum_{i=1}^{r} \sum_{j=1}^{n_{i}} j \cdot c r_{i} \cdot \operatorname{Pr}\left\{\operatorname{Num}_{i}(w)=j\right\}=\sum_{i=1}^{r} \sum_{j=1}^{n_{i}} j \cdot c r_{i} \cdot\left[F_{i}^{(j)}\left(w, \lambda_{i}\right)-F_{i}^{(j+1)}\left(w, \lambda_{i}\right)\right]$

In Equation (10), the prediction of the demand for spare parts in the sales period, $T$, is based on $w$, which is typically longer than the sales period: $w=k_{1} . T$. For a more detailed explanation regarding this topic, refer to Appendix B.

\subsubsection{Suppliers in the after-sales supply chain}

In the previous section, it is shown that the following stock quantity of Component $i$ is required for a local reliability of $r l_{1}$ in the after-sales SC's retailer:

$$
x_{i}=x \cdot E_{i}\left(w, n_{i}\right)+\left(z_{r l_{1}} \cdot \sqrt{x, \sigma_{i}^{2}\left(w, n_{i}\right)}\right) \quad(\forall i=1,2, \ldots, r)
$$

These quantities of components are ordered directly by the retailer from their corresponding suppliers. Hence, the supplier of Component $i$ should not only produce and supply $\Delta x+x$ units of Component $i$ to the manufacturer to assemble and produce the final product but also produce and supply $x_{i}$ units of 
Component $i$ to the chain's retailer to substitute the failed Components $i$ of the returned products that have already been repaired $n_{i}$ times. Thus, the total component order received by Supplier $i$ is $x_{i}+\Delta x+x$ units. However, to compensate for the nonconforming output of its production system, it should plan to produce some additional components, represented by $\Delta \hat{x}_{i}$. In Section 3.1.3, the quantity of $\Delta \hat{x}_{i}$ was determined by assuming that $\Delta x+x$ component units are ordered from this supplier. However, as explained here, in addition to this order for the forward SC, another order with $x_{i}$ quantity is received from the after-sales SC. In this section, we revise the quantity of $\Delta \hat{x}_{i}$ to consider the requirements of the after-sales SC. By following the approach described in Section 3.1.3 and the local reliability of the suppliers, $r l_{s}$, the additional production quantity of the suppliers should be modified as follows:

$$
\Delta \hat{x}_{i}=\frac{y_{i}}{1-\gamma_{i}}\left[\frac{P R_{1 i}}{\mu_{i}} \ln \left(r l_{3}\right)+x_{i}+\Delta x+x\right] \quad(\forall i=1,2, \ldots, r)
$$

We assume that the shortage in fulfilling the component order is divided proportionally between the order of the manufacturer and the order of the retailer. In this case, we are confident with a probability of $r l_{3}$ that the conforming output of Supplier $i$ can fulfill the order of the retailer. With a stock of $x_{i}$ of

Component $i$, the retailer is confident with a probability of $r l_{1}$ that it can respond to all Component $i$ substitutions needed to repair the returned products. Therefore, the after-sales SC is confident with a probability of $r l_{1}, r l_{3}$ that it will be able to respond to all Component $i$ substitutions needed for the returned products inside the sale period. By considering all key components of the product, the after-sales SC's service level is $s l_{a}=\left(r l_{1}, r l_{3}\right)^{r}$.

\subsection{Mathematical Model for Concurrent Flow Planning in the Supply Chains}

The appropriate selection of local reliabilities in different echelons of the SCs and the warranty time is critical for our problem. As described in the previous sections, the chains' service levels in the pre- and after-sales markets are functions of these reliabilities. Higher local reliabilities increase the company's service levels and thus quantity of sales in the pre-market. Alternately, higher reliabilities lead to higher 
production volumes in the facilities, which incur more costs to the system. The same issue is true for the warranty time. Longer warranty times make the product more attractive to customers and also increase the pre-market's demand quantity. However, longer warranty times also impose more after-sales costs on the system. By considering all of these tradeoffs and interactions among the forward and after-sales SCs, we develop a comprehensive mathematical model to determine the best service levels and warranty times for the company in its pre- and after-sales markets, and they preserve the best local reliabilities and flow plan to maximize the company's total profit. This mathematical model is formulated as follows:

$$
\begin{aligned}
& \operatorname{Max} \Pi= \\
& \begin{array}{c}
\left(p-h^{+} \cdot E\left[G^{-1}\left(\operatorname{Max}\left\{r l_{1}, \frac{h^{-}}{h^{-}+h^{+}}\right\}\right)-\varepsilon\right]^{+}-h^{-} \cdot E\left[\varepsilon-G^{-1}\left(\operatorname{Max}\left\{r l_{1}, \frac{h^{-}}{h^{-}+h^{+}}\right\}\right)\right]^{+}\right. \\
-c r) \cdot D\left(p, r l_{1} \cdot r l_{2} \cdot r l_{3}{ }^{r},\left(r l_{1}, r l_{3}\right)^{r}, w\right)
\end{array} \\
& -\left[\sum_{i=1}^{r}\left(a_{1 i}+a_{2 i}\right) \cdot\left(x+\Delta x+x_{i}+\Delta \dot{x}_{i}\right)+\sum_{i=1}^{r} \frac{h_{1 i} i\left(x+\Delta x+x_{i}\right)^{2}}{2 \cdot P R_{1 i}}+\sum_{i=1}^{r} b_{1 i} \cdot(x+\Delta x)+\right. \\
& \left.b_{2} \cdot(x+\Delta x)+\frac{h_{2} \cdot(x)^{2}}{2 \cdot P R_{2}}+\left(c_{1}+c_{2}\right) \cdot x+\sum_{i=1}^{r} c_{3 i} \cdot x_{i}\right]
\end{aligned}
$$

Subject to

$$
\begin{array}{ll}
x=D\left(p, r l_{1} \cdot r l_{2} \cdot r l_{3}{ }^{r},\left(r l_{1} \cdot r l_{3}\right)^{r}, w\right) \cdot G^{-1}\left(\operatorname{Max}\left\{r l_{1}, \frac{h^{-}}{h^{-}+h^{+}}\right\}\right) & \\
\Delta x=G^{\prime-1}\left(r l_{2}\right) \cdot x & \\
x_{i}=x \cdot E_{i}\left(w_{,} n_{i}\right)+\left(z_{r l_{1}} \cdot \sqrt{x \cdot \sigma_{i}^{2}\left(w, n_{i}\right)}\right) & (\forall i=1,2, \ldots, r) \\
\Delta x_{i}=\frac{\gamma_{i}}{1-\gamma_{i}}\left[\frac{P R_{1 i}}{\mu_{i}} \ln \left(r l_{3}\right)+x+\Delta x+x_{i}\right] & (\forall i=1,2, \ldots, r) \\
0 \leq r l_{1}, r l_{2}, r l_{3} \leq 1 & \\
w \geq 0 &
\end{array}
$$

The first term of the objective function is used to compute the profit captured by the retailer of the company in the pre-market. In this term, the average additional inventory, average shortage and average repair costs are removed from the captured income (see Equations 4 and 11). The second term is the sum of procurement, production, inventory holding, and transportation costs throughout the forward and after- 
sales SCs. The first item of the second term is the sum of procurement and production costs in the suppliers. The second and fifth items are the inventory holding costs in the suppliers and manufacturer, respectively. The third and seventh items are the product transportation costs from the suppliers to the manufacturer and the spare parts transportation costs from the suppliers to the retailer, respectively. The fourth term is the manufacturing cost of the manufacturer. The sixth term is the sum of the transportation costs from the manufacturer to the retailer and the handling cost of the retailer. Equations (14)-(17) represent the relationships between the local reliability of the facilities and their production volumes.

This model is a nonlinear formulation with highly nonlinear terms in the objective function and constraints. The forms of some of these terms are not fixed and depend on the density functions of the uncertainties (Equations 14 and 15). Solving this type of model is not straightforward. However, our model has some unique characteristics that differentiate it from other models. In the next section, we propose a solution approach to solve the model.

\section{SOLUTION APPROACH}

Not only is the model proposed in Section 3 for concurrent flow planning in the forward and after-sales SCs highly nonlinear, but the mathematical forms of some of its nonlinear terms, such as Equations (14) and (15), also depend on the density functions considered for modeling uncertainty. This means that changing the type of density function causes the mathematical form of these terms to change. This makes solving the model even more challenging. Alternately, important design variables, such as $r l_{1}, r l_{2}$, and $r l_{3}$, take values on a highly restricted interval, $[0,1]$; it is also reasonable to assume that this interval is $[0.5,1.0]$ (if we ignore density functions and only consider their medians in the problem, we can easily preserve a 0.5 reliability for facilities; therefore, the main challenge occurs when we look for higher reliabilities for facilities). In addition, in reality, warranty lengths of 6 months, 1 year, 18 months and 2 years are common. These properties of this model make discretization an appropriate method for solving it. 
To discretize the model, it is necessary to define some new notations. $R L 3=\left\{r l 3^{1}, r l 3^{2}, \ldots, r l 3^{|R L 3|}\right\}$, $R L 2=\left\{r l 2^{1}, r l 2^{2}, \ldots, r l 2^{|R L 2|}\right\}$, and $R L 1=\left\{r l 1^{1}, r l 1^{2}, \ldots, r l 1^{|R L 1|}\right\}$ are defined as sets of scenarios for the local reliability of the suppliers, manufacturer, and retailer, respectively. For scenario selections from these sets, we must define some new binary variables. The binary variables $y_{r l 1^{i}}\left(\forall r l 1^{i} \in R L 1\right)$, $y_{r l 2^{i}}\left(\forall r l 2^{i} \in R L 2\right)$, and $y_{r l 3^{i}}\left(\forall r l 3^{i} \in R L 3\right)$ are equal to 1 if the local reliabilities $r l 1^{i}, r l 2^{i}$ and, $r l 3^{i}$ are selected from the sets $R L 1, R L 2$, and $R L 3$ for the retailer, manufacturer and suppliers, respectively; otherwise, they are equal to 0 . In the same manner, we define a set of warranty lengths $W=\left\{w^{1}, w^{2}, \ldots, w^{|W|}\right\}$ and binary design variables $z_{w^{i}}\left(\forall W^{i} \in W\right)$ for warranty selection from this set. Only one local reliability and warranty length can be selected from these sets:

$$
\begin{aligned}
& \sum_{i=1}^{|R L 1|} y_{r l 1^{i}}=1 \\
& \sum_{i=1}^{|R L 2|} y_{r l 2^{i}}=1 \\
& \sum_{i=1}^{|R L 3|} y_{r l 3^{i}}=1 \\
& \sum_{i=1}^{|W|} z_{w^{i}}=1
\end{aligned}
$$

By defining these new sets and variables, we revise Equations (14-18) to represent the relationships between the production volume and local reliability of the SCs' facilities:

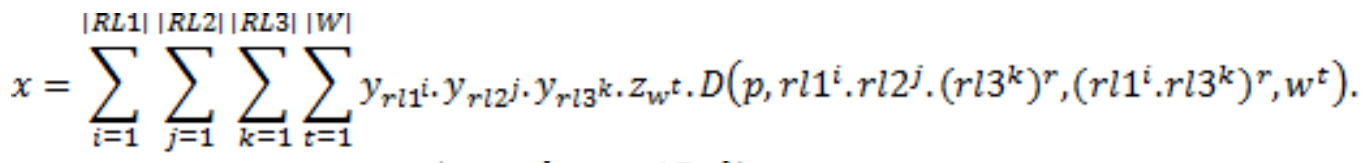

$$
\begin{aligned}
& G^{-1}\left(\operatorname{Max}\left\{r l 1^{i}, \frac{h^{-}}{h^{-}+h^{+}}\right\}\right) \\
& \Delta x=\sum_{i=1}^{\|R L 1\|} \sum_{j=1} \sum_{k=1} \sum_{t=1}^{|R L 2|} y_{r l 1^{i}} y_{r l 2^{j}} \cdot y_{r l 3^{k}} \cdot z_{W^{t}} \cdot G^{g^{-1}}\left(r l 2^{j}\right) \cdot D\left(p, r l 1^{i} \cdot r l 2^{j} \cdot\left(r l 3^{k}\right)^{r},\left(r l 1^{i} \cdot r l 3^{k}\right)^{r}, W^{t}\right) . \\
& G^{-1}\left(\operatorname{Max}\left\{r l 1^{i}, \frac{h^{-}}{h^{-}+h^{+}}\right\}\right) \\
& x_{i}=\sum_{i=1}^{\|R L 1|\|R L 2\|| R L 3\|} \sum_{j=1}^{\|W\|} \sum_{k=1}^{\|W\|} y_{r l 1^{i}} y_{r l 2^{j}} \cdot y_{r l 3^{k}} \cdot z_{w^{t}}
\end{aligned}
$$




$$
\begin{gathered}
{\left[D\left(p, r l 1^{i} \cdot r l 2^{j} \cdot\left(r l 3^{k}\right)^{r},\left(r l 1^{i}, r l 3^{k}\right)^{r}, w^{t}\right) \cdot G^{-1}\left(\operatorname{Max}\left\{r l 1^{i}, \frac{h^{-}}{h^{-}+h^{+}}\right\}\right) \cdot E_{i}\left(w^{t}, n_{i}\right)+\right.} \\
\left.\left(z_{r l 1^{i}} \cdot \sqrt{D\left(p, r l 1^{i} \cdot r l 2^{j} \cdot\left(r l 3^{k}\right)^{r},\left(r l 1^{i}, r l 3^{k}\right)^{r}, w^{t}\right) \cdot G^{-1}\left(\operatorname{Max}\left\{r l 1^{i}, \frac{h^{-}}{h^{-}+h^{+}}\right\}\right) \cdot \sigma_{i}^{2}\left(w^{t}, n_{i}\right)}\right)\right] \\
(\forall i=1,2, \ldots, r)
\end{gathered}
$$

$$
\begin{aligned}
& \Delta \dot{x}_{i}
\end{aligned}
$$

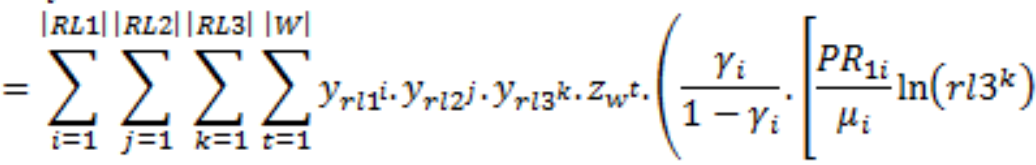

$$
\begin{aligned}
& +\left(G^{r^{-1}}\left(r l 2^{j}\right)+1\right) \cdot D\left(p, r l 1^{i} \cdot r l 2^{j} \cdot\left(r l 3^{k}\right)^{r},\left(r l 1^{i} \cdot r l 3^{k}\right)^{r}, w^{t}\right) \cdot G^{-1}\left(\operatorname{Max}\left\{r l 1^{i}, \frac{h^{-}}{h^{-}+h^{+}}\right\}\right) \\
& +D\left(p, r l 1^{i} \cdot r l 2^{j} \cdot\left(r l 3^{k}\right)^{r},\left(r l 1^{i} \cdot r l 3^{k}\right)^{r}, w^{t}\right) \cdot G^{-1}\left(\operatorname{Max}\left\{r l 1^{i}, \frac{h^{-}}{h^{-}+h^{+}}\right\}\right) \cdot E_{i}\left(w^{t}, n_{i}\right) \\
& \left.\left.+z_{r l 1^{i}} \sqrt{D\left(p, r l 1^{i} \cdot r l 2^{j} \cdot\left(r l 3^{k}\right)^{r},\left(r l 1^{i} \cdot r l 3^{k}\right)^{r}, w^{t}\right) \cdot G^{-1}\left(\operatorname{Max}\left\{r l 1^{i}, \frac{h^{-}}{h^{-}+h^{+}}\right\}\right) \cdot \sigma_{i}^{2}\left(w^{t}, n_{i}\right)}\right]\right) \\
& (\forall i=1,2, \ldots, r)
\end{aligned}
$$

After substituting these equations into the objective function (Equation 13) and linearizing the multiplication of binary variables, the mathematical model of the problem is transformed into a mixed integer linear model with binary variables, which can be solved globally using software as CPLEX, GAMS, GROOBI or LINGO. We used CPLEX to solve this model (for the entire linearized mathematical model, refer to Appendix C).

\section{RESULTS AND DISCUSSION}

This section considers a company that produces and supplies a durable consumer product to a target market with a stochastic and elastic demand function for the retail price $p=\$ 10.00$. This product includes two critical components, Components 1 and 2. Components 1 and 2 are manufactured by Suppliers 1 and 2 with procurement and production costs of $a_{11}+a_{21}=\$ 3.00$ and $a_{12}+a_{22}=\$ 2.50$, respectively. Then, these components are transported to the manufacturer and assembled into the final product with a cost of $b_{2}+b_{11}=b_{2}+b_{12}=\$ 1.00$. After that, the final products are transported and handled by the retailer with a cost of $c_{1}+c_{2}=\$ 0.5$. Based on historical sales, the average product 
demand in the pre-market is treated as a linear function of the retail price, warranty time and service levels: $D\left(p, s l_{p}, s l_{\alpha}, w\right)=500+200 \times w-250 \times(p-10)-500 \times\left(1-s l_{a}\right)-900 \times\left(1-s l_{p}\right)$.

The products of this company are offered with a warranty. The company has four options for the warranty length: $6,12,18$, or 24 months. Dead inventory and lost sales at the end of the sales period impose costs of $h^{-}=\$ 0.10$ and $h^{+}=\$ 0.15$ on the company, respectively. Components 1 and 2 of this product have reliability parameters $\lambda_{1}=0.1$ and $\lambda_{2}=0.4$. Component 1 is not repairable. Thus, if the failure of a returned product inside the warranty time is due to Component 1 , then that part is replaced with a new one by the retailer. However, the circumstances are different for Component 2. It is more economical to repair Component 2 the first time it fails, but after the first failure, it is substituted with a new component. Similar to the final product, the required components for repairing returned products should be produced and stored in the retailer before the beginning of the sale period. The components are produced in the first and second suppliers with production rates (number per time unit) of $P R_{1}=8000$ and $P R_{2}=9000$, respectively. The average deterioration times in the first and second suppliers are similar and equal to $1 / \mu_{1 \text { and } 2}=0.5$. After deterioration, 10 and 20 percent of Component 1 and Component 2 production in the first and second suppliers is non-conforming $\left(\gamma_{1}=0.10\right.$ and $\left.\gamma_{1}=0.20\right)$. The uncertain part of the pre-market's demand function, $\varepsilon$, is normally distributed with a mean of 0.0 and variance of 1.0. In addition, the flawed production rate for the manufacturer is uniformly distributed over the range $[0, \beta=0.15]$. Components 1 and 2 produced by Suppliers 1 and 2 for after-sales market operations are transported directly to the retailer with transportation costs $c_{31}=c_{32}=\$ 1.00$. Solving the mathematical model of this problem leads to the following results: the local reliabilities in the retailer, manufacturer, and suppliers are $r l_{1}=0.99, r l_{2}=0.99$ and $r l_{3}=0.88$, respectively. The best warranty option is 6 months. To preserve these local reliabilities, $x=552.7$ product units are ordered by the retailer from the manufacturer. To fulfill this order of the retailer, the manufacturer plans to manufacture $\Delta x=82.07$ additional product units to compensate for the malfunction of its system. To produce this 
product volume, the required components are ordered from the corresponding suppliers. In addition to this component order from the manufacturer, the suppliers receive another order from the retailer, $x_{i}(i=1$ and 2$)$, to provide the required components for repairing returned products. Similarly, the first and second suppliers plan to procure and produce $\Delta x_{1}=18.14$ and $\Delta x_{2}=19.46$ additional units of Component 1 and Component 2, respectively, to compensate for defective production in their production systems. This flow planning leads to a profit of $\Pi=\$ 715.3$ for the company, which is the highest in retail price $p=\$ 10.00$.

\section{Figure 4 goes about here}

As explained before, the local reliability of imperfect facilities has a critical role in the service levels provided by the SCs in the pre- and after-sales markets. Increasing local reliabilities causes an increase in service levels, which leads to higher product demand and higher income. Alternately, a higher local reliability in a facility means higher production in that facility, which imposes a higher cost. Therefore, the reliabilities of facilities should be determined in such a way as to facilitate an appropriate tradeoff between their imposing cost and income. Figures 5 and 6 present the profit of the company, $\tilde{\Pi}$, with respect to its service level in the pre-market, $s l_{p}=r l_{1} \cdot r l_{2} \cdot r l_{3}{ }^{2}$, and the after-sales market, $s l_{\alpha}=\left(r l_{1}, r l_{3}\right)^{2}$, respectively. Because the service levels are functions of local reliabilities, there are several local reliability triples, $\left(r l_{1}, r l_{2}, r l_{3}\right)$, that may lead to a single service level, which is why there is more than one profit value in Figures 5 and 6 for each service level. Each value corresponds to one $\left(r l_{1}, r l_{2}, r l_{3}\right)$ triple, which leads to the following observation:

Observation 1: In SCs with imperfect facilities, it is not sufficient to find the best service level; it is also necessary to find the least costly local reliability triples, $\left(r l_{1}{ }^{8}, r l_{2}{ }^{8}, r l_{3}{ }^{8}\right)$, corresponding to that service level. 
For example, in Figure 5, all of the points along the yellow arrow correspond to $\left(r l_{1}, r l_{2}, r l_{3}\right)$ triples, leading to $s l_{p}{ }^{*}=0.76$. As seen, the profits of the companies corresponding to these triples differ significantly. Solving the proposed mathematical model helps us to find the least costly triple that is equal to $\left(r l_{1}{ }^{*}=0.99, r l_{2}{ }^{*}=0.99, r l_{3}{ }^{*}=0.88\right)$.

In the model proposed in this paper and the sample problem solved in this section, the retail price of the product is assumed to be a fixed exogenous factor. However, the retail price has always been one of the most important completitive factors for rivals in the markets. Determining $g_{\mathbb{I}}$ the appropriate retail price is not straightforward because of its conflicting effects on the company's sales volume and unit marginal profit. The price increment augments the unit marginal profit of each sale but reduces the attractiveness of the product for customers and leads to lower sales volume. In the remainder of this section, we analyze the correlation between the retail price and after-sales service of the company via sensitivity analysis. It is assumed that the retail price of the product can be selected on the [\$9.0, $\$ 13.5]$ interval. This interval is determined by different factors, such as the retail price of similar rival or substitutable products and governmental regulations to support domestic production or customers. The mathematical model of the problem is solved for different values of the price on the [\$9.0, \$13.5] interval and different variants of the warranty time. The results are shown in Figure 7.

As seen in Figure 7, the price increment has similar effects on the company's profit for different warranty length options. Initially, the price increment leads to a higher profit for the company because the positive effect of unit marginal profit increment on the profit of the company dominates the negative effect on the sales reduction. Thus, the company's profit gradually starts to increase. For the 6-month warranty length, the highest profit is achieved for $p^{*}=\$ 10.75$, which is equal to $\Pi=\$ 782.20$. At this price, the difference between the positive and negative effects of the price increment becomes zero, and beyond that, its negative effect dominates the positive effect. Thus, the company's profit starts to decrease. Therefore, the retail price increments have heterogeneous effects on the company's profit for all warranty options. According to Figure 7, by increasing the warranty length, the profit function shifts to the right. 
This means that a higher retail price is needed to preserve the same profit value for a longer warranty length. Therefore, there is a positive correlation between price and warranty length. These results are summarized in the following observations:

Observation 2: Increases/decreases in the price have a heterogeneous effect on the company's profit for all warranty options, meaning that the $\frac{\Delta \Pi}{\Delta p}$ ratio is not constant for different $p$ values. For each warranty option, $w$, this effect is positive for all price values less than the optimal price of that warranty option, $p_{w}^{*}$. For price values greater than $p_{w}^{*}$, this effect is negative. Therefore, managers should be careful, as any price increment beyond $p_{w}^{*}$ is not advisable for each warranty option.

Observation 3: A longer warranty length imposes a higher cost on a company, which is compensated for by a higher price value. Therefore, changing the warranty strategy for a product requires a positively correlated change in the retail price of that product.

\section{Figure 7 goes about here.}

Now, we seek to determine the best priority for the warranty options for different price values. The priority of a warranty option is determined by its profitability. This means that a warranty option with the highest priority is the most profitable (optimal) one. However, by determining the priority of all warranty options, we provide more information for decision makers regarding the profitability of the other warranty options. For this purpose, we solve the mathematical model of the test problem for different values of the retail price and different warranty options. Then, a function representing the profit function of the company for each warranty length with respect to the retail price values is fitted. These functions are shown in Figure 7. These profit functions have several intersections, indicated by red dots in this figure. These dots represent critical retail price values at which the priority and profitability of the warranty options change. In the test problem, these critical price values are $p_{1}=11.25, p_{2}=11.57, p_{3}=11.82, p_{4}=12.07$, and $p_{5}=12.37$. According to Figure 7 , in the first 
price interval $^{1}$, [\$9.00, $\left.\$ 11.25\right]$, the profit function corresponding to $w=6$ (months) is the highest function, which means that it is the most profitable one. Therefore, $w^{*}=6$ (months) is the optimal warranty option and has the highest priority. After $w=6$ (months), the second highest function corresponds to $w=12$ (months). This means that the $w=12$ (months) warranty option is the second most profitable warranty option and that its priority order is 2 . In the same manner, the $w=18$ (months) and $w=25$ (months) warranty options have the third and fourth priorities, respectively. Thus, the priority order of the warranty options in the first price interval is $6,12,18$, and 24 (months). In the second price interval ${ }^{2},[\$ 11.25, \$ 11.57]$, the priority order of the profit functions changes to $12,6,18$, and 24 (months). This means that the optimal warranty option is $w^{*}=12$ (months). The priority order of the warranty options in different price intervals is as follows:

- If $p<p_{1}=\$ 11.25 \quad$ then the priority of the warranty options is: $6,12,18$ and 24 months.

- If $p_{1}<p \leq p_{2}=\$ 11.57$ then the priority of the warranty options is: $12,6,18$ and 24 months.

- If $p_{2}<p \leq p_{3}=\$ 11.82$ then the priority of the warranty options is: $12,18,6$ and 24 months.

- If $p_{3}<p \leq p_{4}=\$ 12.07$ then the priority of the warranty options is: 18, 12, 24 and 6 months.

- If $p_{4}<p \leq p_{5}=\$ 12.37$ then the priority of the warranty options is: $18,24,12$ and 6 months.

- If $p_{5}=12.37<p \quad$ then the priority of the warranty options is: $24,18,12$ and 6 months.

Based on these results, the best warranty strategy in different price intervals is summarized in Table 3.

\section{Table 3 goes about here}

These results are summarized in the following observation:

\footnotetext{
${ }^{1}$ The lower bound of this interval is the lower bound of the feasible price interval, [\$9.0, $\left.\$ 13.5\right]$, and the upper bound is the first critical price value.

${ }^{2}$ The lower and upper bounds of this interval are equal to the first and second critical price values, respectively.
} 
Observation 4: The priority order of the warranty options changes with the critical price values, but it remains stable in the price intervals between two sequential critical price values.

Next, we analyze how this behavior changes in price- and warranty-sensitive markets. We first start with price-sensitive markets. For this purpose, the price sensitivity parameter of the pre-market is doubled (an increase from 250 to 500), and all of the models are re-computed with this new parameter. The results are summarized in Figure 8. In the price-sensitive market, the priority order of the warranty options is as follows:

- If $\quad p<p_{1}=\$ 10.90 \quad$ then the priority of the warranty options is: 6, 12, 18 and 24 months.

- If $p_{1}<p \leq p_{2}=\$ 11.05$ then the priority of the warranty options is: $12,6,18$ and 24 months.

- If $p_{2}<p \leq p_{3}=\$ 11.20$ then the priority of the warranty options is: 12, 18, 6 and 24 months.

- If $p_{3}<p \leq p_{4}=\$ 11.38$ then the priority of the warranty options is: $18,12,24$ and 6 months.

- If $p_{4}<p \leq p_{4}=\$ 11.55$ then the priority of the warranty options is: $18,24,12$ and 6 months.

- If $p_{4}<p \quad$ then the priority of the warranty options is: $24,18,12$ and 6 months.

Table 4 summarizes the best warranty strategy in different price intervals based on these results.

\section{Table 4 goes about here}

As seen in Figure 8, the optimal price for all of the warranty functions shifts to the left. This means that in price-sensitive markets, the highest profit of the company occurs at lower retail prices regardless of the warranty length. Alternately, the differences between the profit functions of the warranty options become more significant. This means that an inappropriate selection of the warranty length leads to a higher profit loss in this market compared with less price-sensitive markets. In addition, the price intervals between the critical retail price values in which the priority of the warranty options changes become smaller. In this type of market, the priority of the warranty options is more fragile and changes more rapidly with retail price variations. These outcomes leads to Observation 5. 
Observation 5: An inappropriate warranty length for products leads to higher profit loss in markets with higher price sensitivity. In addition, the priority order of the warranty options is more fragile in these markets and remains stable within smaller price intervals. Even a small change in the price may change the most profitable warranty option. This means that managers of companies working in price-sensitive markets should be more careful with respect to price changes. It is more likely that a small change in the retail price requires a new warranty strategy.

\section{Figure 8 goes about here.}

Next, we analyze how this behavior changes in warranty-sensitive markets. For this purpose, the warranty sensitivity parameter of the market in the problem is doubled (an increase from 200 to 400 ), and all of the models are re-computed with this new parameter. The results are summarized in Figure 9.

In the warranty-sensitive market, the priority order of the warranty options is as follows:

- If $\quad p<p_{1}=\$ 11.17$ then the priority of the warranty options is: 6, 12, 18 and 24 months.

- If $p_{1}<p \leq p_{2}=\$ 11.57$ then the priority of the warranty options is: $12,6,18$ and 24 months.

- If $p_{2}<p \leq p_{3}=\$ 11.95$ then the priority of the warranty options is: $12,18,6$ and 24 months.

- If $p_{3}<p \leq p_{4}=\$ 12.40$ then the priority of the warranty options is: 18, 12, 24 and 6 months.

- If $p_{4}<p \leq p_{4}=\$ 12.75$ then the priority of the warranty options is: $18,24,12$ and 6 months.

- If $p_{4}<p \quad$ then the priority of the warranty options is: 24, 18, 12 and 6 months.

\section{Figure 9 goes about here}

Table 5 presents the best warranty strategy in different price intervals based on these results.

Table 5 goes about here 
As seen in Figure 9, in this case, the warranty options with higher lengths are more attractive, and the highest profit is achieved with the $w^{*}=24$ (months) warranty option. Furthermore, a longer warranty length justifies the optimality of a higher retail price in this market, as the positive effect of the warranty increment dominates the negative effects of price augmentation on the market's demand volume. The optimal retail price is $p^{*}=\$ 13.30$ in this case. In warranty-sensitive markets, the critical priority changing causes the price points to become farther away from each other. This means that the optimal warranty strategy is more stable in this market and that the priority of the warranty options is more stationary with respect to variations in the retail price. These results are summarized in Observation 6.

Observation 6: In warranty-sensitive markets, the optimal retail prices are higher and the price intervals between sequential critical price values are larger. This means that the optimal warranty strategy of companies and the priority order of their warranty options are stationary in a larger price interval. In other words, managers of companies working in warranty-sensitive markets do not need to be particularly concerned with small price variations that occur far from the critical price values.

\section{CONCLUDING REMARKS}

In this paper, we develop a mathematical model that can determine the most profitable integrated production plan for companies servicing both pre- and after-sales markets. Uncertainty in the performance of production facilities, called supply-side uncertainties, and demands of markets, called demand-side uncertainties, are considered in this model. Having an integrated production plan is critical for the companies because in addition to having to address two SCs (i.e., forward and after-sales SCs), these chains are not independent. The events occurring in one SC affect the performance of the other chain. In this paper, we identified two interactions between the chains that justify the necessity of their integrated and concurrent flow planning. This model fills the "lack of holistic perspective and system integration among SC partners" gap raised by both industrial managers and academic researchers. The contributions of this work to the literature are as follows: 
- Integration in after-sales activities: In addition to the downstream marketing effects of the aftersales services, we also incorporate their support of upstream manufacturing operations in our model. This integration strengthens the holistic perspective and system integration among facilities involved in after-sales activities.

- Integration of forward and after-sales SCs: The interactions between the operations of the forward and after-sales SCs are typically ignored in the literature, and they are planned separately. These interactions are quantified and incorporated in our integrated model. Incorporating these interactions not only improves demand and required inventory predictions in pre- and after-sales markets but also strengthens the holistic perspective and system integration in product/after-sales service provider companies.

- Managing supply-side uncertainties in SCs: The performances of production facilities are typically assumed to be perfect in the SC literature. In this paper, we consider that inherent uncertainties exist in imperfect production systems of the practical world. To improve the service level in pre- and after-sales markets and mitigate qualified flow depreciation in SCs with imperfect facilities, we suggest that orders should be amplified from the downstream to the upstream of the SCs.

Analyzing the computational results of the model reveals some interesting insights:

- In SCs with imperfect facilities, it is not sufficient to determine the best service level; it is also necessary to find the least costly local reliability triples corresponding to that service level.

- Increases/decreases in price have a heterogeneous effect on the company's profit for all warranty options. However, changing the warranty strategy for a product requires a positively correlated change in the retail price of that product. 
- The priority order of the warranty options changes for the critical price values, but it remains stable in the price intervals between two sequential critical price values. These orders are more fragile in price-sensitive markets and more stable in warranty-stable markets.

The model presented in this paper is applicable for companies supplying durable consumer products with failure-free warranties for customers. Customers are informed by the companies' retailers about the after-sales service level commitment, or this information is available for customers through their own evaluation or viewing of independent Internet product-service evaluation websites.

Although this work focuses on durable consumer products for which repairing the returned products is the main responsibility of the after-sales SCs and a failure-free warranty strategy is considered, this formulation can be modified for other product types with different warranty strategies, e.g., nonrepairable products with rebate warranties. In addition, the concepts developed here can be modified to make them applicable for capital goods, such as computer networks, medical and defense systems, and infrastructure, for which performance-based contracts are common. In these industries, the development, installation, or construction of systems is completed by forward SCs, and the maintenance of such systems to keep them performing at an acceptable level of availability is the responsibility of after-sales SCs.

\section{ACKNOWLEDGMENT}

We gratefully acknowledge support from the NSF grant ECCS-1128826, L.A. Comp Chair and the John and Mary Moore Chair at the University of Oklahoma and Entercoms Inc of Dallas, Texas.

\section{REFERENCES}

Allon, G., Federgruen, A., 2009. Competition in service industries with segmented markets. Manag. Sci. 55(4), 619-634. doi:10.1287/mnsc.1080.0946.

Anderson, E.E., 1977. Product price and warranty terms: an optimization model. J. Oper. Res. Soc. 28(3), 739-741. doi:10.1057/jors.1977.150. 
Bacchetti, A., Saccani, N., 2012. Spare parts classification and demand forecasting for stock control: investigating the gap between research and practice. Omega 40(6), 722-737. doi:10.1016/j.omega.2011.06.008.

Baghalian, A., Rezapour, S., Farahani, R.Z., 2013. Robust supply chain network design with service level against disruptions and demand uncertainties: A real-life case. Eur. J. Oper. Res. 227(1), 199-215. doi:10.1016/j.ejor.2012.12.017.

Baines, T., Lightfoot, H., Evans, S., Neely, A., Greenough, R., Peppard, J., Roy, R., Shehab, E., Braganza, A., Tiwari, A., Alcock, J., Angus, J., Bastl, M., Cousens, A., Irving, P., Johnson, M., Kingston, J., Lockett, H., Martinez, V., Michele, P., 2007. State-Of-the-Art in Product-Service Systems. Proceedings of the Institution of Mechanical Engineers - Part B - Engineering Manufacture. 221(10); 1543-1552.

Barabadi, A., Barabady, J., Markeset, T., 2014. Application of reliability models with covariates in spare part prediction and optimization - A case study. Reliab. Eng. Syst. Saf. 123, 1-7. doi:10.1016/j.ress.2013.09.012.

Bernstein, F., Federgruen, A., 2004. A general equilibrium model for industries with price and service competition. Oper. Res. 52(6), 868-886. doi:10.1287/opre.1040.0149.

Bernstein, F., Federgruen, A., 2007. Coordination mechanisms for supply chains. Manufacturing and service. Oper. Manag. 9(3), 242-262.

Boone, C.A., Craighead, C.W., Hanna, J.B., 2008. Critical challenges of inventory management in service parts supply: a Delphi study. Oper Manag Res 1(1), 31-39. doi:10.1007/s12063-008-0002-2.

Business Week, 2004. Hyundai: kissing clunkers goodbye - A five-year focus on quality has sent customer satisfaction soaring. Business Week, 16 May.

Cardona-Valdés, Y., Álvarez, A., Ozdemir, D., 2011. A bi-objective supply chain design problem with uncertainty. Transport. Res. C - Emer. 19(5), 821-832. 
Chakravarthy, S.R., Gómez-Corral, A., 2009. The influence of delivery times on repairable k-out-of- $N$ systems with spares. Appl. Math. Modell. 33(5), 2368-2387. doi:10.1016/j.apm.2008.07.007.

Chen, J., Chien, Y., 2007. Renewing warranty and preventive maintenance for products with failure penalty post-warranty. Qual. Reliab. Eng. Int. 23(1), 107-121. doi:10.1002/qre.824.

Chen, M.S., Chu, M.C., 2001. The analysis of optimal price control model in matching problem between production and sales. Asia Pac. J. Oper. Res. 18(2), 131-148.

Chen, X., Li, L., Zhou, M., 2012. Manufacturer's pricing strategy for supply chain with warranty perioddependent demand. Omega 40(6), 807-816. doi:10.1016/j.omega.2011.12.010.

Chien, Y., Chen, J., 2008. Optimal spare ordering policy under a rebate warranty. Eur. J. Oper. Res. 186(2), 708-719. doi:10.1016/j.ejor.2007.02.026.

Chien, Y.H., 2005. Determining optimal warranty periods from the seller's perspective and optimal outof-warranty replacement age from the buyer's perspective. Int. J. Syst. Sci. 36(10), 361-367.

Chu, J., Chintagunta, P.K., 2009. Quantifying the economic value of warranties in the U.S. Server Market. Mark. Sci. 28(1), 99-121. doi:10.1287/mksc.1080.0380.

Cohen, M.A., Agrawal, N., 2006. Winning in the aftermarkets. Harv. Bus. Rev. 84(5) 129-138.

Daniel, J.S.R., Rajendran, C., 2006. Heuristic approaches to determine base-stock levels in a serial supply chain with a single objective and with multiple objectives. Eur. J. Oper. Res. 175(1), 566-592. doi:10.1016/j.ejor.2005.04.039.

de Smidt-Destombes, K.S., van der Heijden, M.C., van Harten, A., 2006. On the interaction between maintenance, spare part inventories and repair capacity for a k-out-of-N system with wear-out. Eur. J. Oper. Res. 174(1), 182-200. doi:10.1016/j.ejor.2005.02.043. 
de Smidt-Destombes, K.S., van der Heijden, M.C., van Harten, A., 2007. Availability of k-out-of- $N$ systems under block replacement sharing limited spares and repair capacity. Int. J. Prod. Econ. 107(2), 404-421. doi:10.1016/j.ijpe.2006.08.013.

de Smidt-Destombes, K.S., van der Heijden, M.C., van Harten, A., 2009. Joint optimization of spare part inventory, maintenance frequency and repair capacity for k-out-of- $N$ systems. Int. J. Prod. Econ. 118(26), 0-8.

Dell.com web site, 2010. URL: http://www.dell.com/home/ (accessed on April 28, 2010).

Dennis, M.J., Kambil, A., 2003. Service management: building profits after the sale. Supply Chain Manag. Rev. 7(1), 42-48.

Díaz, A., Fu, M.C., 1997. Models for multi-echelon repairable item inventory systems with limited repair capacity. Eur. J. Oper. Res. 97(3), 480-492. doi:10.1016/S0377-2217(96)00279-2.

Esmaeili, M., Gamchi, N., Asgharizadeh, E., 2014. Three-level warranty service contract among manufacturer, agent and customer: A game-theoretical approach. Eur. J. Oper. Res. 239(1), 177186. doi:10.1016/j.ejor.2014.04.045.

Faridimehr, S., Niaki, S.T.A., 2012. A note on optimal price, warranty length and production rate for free replacement policy in static demand markets. Omega 40(6), 805-806.

doi:10.1016/j.omega.2011.12.009.

Finkelstein, M., 2009. On systems with shared resources and optimal switching strategies. Reliab. Eng. Syst. Saf. 94(8), 1358-1362. doi:10.1016/j.ress.2009.02.006.

Gallagher, T., Mitchke, M.D., Rogers, M.D., 2005. Profiting from spare parts. McKinsey Quarterly 2, 14.

Glickman, T.S., Berger, P.D., 1976. Optimal price and protection period decisions for a product under warranty. Manag. Sci. 22(12), 1381-1390. doi:10.1287/mnsc.22.12.1381. 
Graves, S.C., 1985. A multi-echelon inventory model for a repairable item with one-for-one replenishment. Manag. Sci. 31(10), 1247-1256. doi:10.1287/mnsc.31.10.1247.

Gross, D., Pinkus, C.E., 1979. Designing a support system for repairable items. Comput. Oper. Res. 6(2), 59-68. doi:10.1016/0305-0548(79)90017-0.

Hsu, C., Li, H., 2011. Reliability evaluation and adjustment of supply chain network design with demand fluctuations. Int. J. Prod. Econ. 132(1), 131-145. doi:10.1016/j.ijpe.2011.03.020.

Huang, H., Liu, Z., Murthy, D.N.P., 2007. Optimal reliability, warranty and price for new products. IIE Transactions 39(8), 819-827. doi:10.1080/07408170601091907.

Hussain, A.Z.M.O., Murthy, D.N.P., 2000. Warranty and optimal redundancy with uncertain quality. Math. Comput. Modell. 31(10-12), 175-182. doi:10.1016/S0895-7177(00)00085-6.

Hussain, A.Z.M.O., Murthy, D.N.P., 2003. Warranty and optimal reliability improvement through product development. Math. Comput. Modell. 38(11-13), 1211-1217. doi:10.1016/S08957177(03)90122-1.

Jhang, J., 2005. The optimal used period of repairable product with lead time after the warranty expiry. Int. J. Syst. Sci. 36(7), 423-431. doi:10.1080/00207720500150978.

Jung, G.M., Park, D.H., 2003. Optimal maintenance policies during the post-warranty period. Reliab. Eng. Syst. Saf. 82(2), 173-185. doi:10.1016/S0951-8320(03)00144-3.

Jung, K.M., Park, M., Park, D.H., 2015. Cost optimization model following extended renewing two-phase warranty. Comput. Ind. Eng. 79, 188-194. doi:10.1016/j.cie.2014.10.016.

Kamrad, B., Lele, S.S., Siddique, A., Thomas, R.J., 2005. Innovation diffusion uncertainty, advertising and pricing policies. Eur. J. Oper. Res. 164(3), 829-850. doi:10.1016/j.ejor.2003.10.046.

Khajavi, S.H., Partanen, J., Holmström, J., 2014. Additive manufacturing in the spare parts supply chain. Comput. Ind. 65(1), 50-63. doi:10.1016/j.compind.2013.07.008. 
Kim, B., Park, S., 2008. Optimal pricing, EOL (end of life) warranty, and spare parts manufacturing strategy amid product transition. Eur. J. Oper. Res. 188(3), 723-745. doi:10.1016/j.ejor.2007.04.036.

Kim, S.H., Cohen, M.A., Netessine, S., 2007. Performance contracting in after-sales service supply chains. Manag. Sci. 53(12), 1843-1858. doi:10.1287/mnsc.1070.0741.

Kleber, R., Zanoni, S., Zavanella, L., 2011. On how buyback and remanufacturing strategies affect the profitability of spare parts supply chains. Int. J. Prod. Econ. 133(1), 135-142. doi:10.1016/j.ijpe.2010.04.020.

Ko, H.J., Evans, G.W., 2007. A genetic algorithm-based heuristic for the dynamic integrated forward/reverse logistics network for 3PLs. Comput. Oper. Res. 34(2), 346-366. doi:10.1016/j.cor.2005.03.004.

Kuo, W., Wan, R., 2007. Recent advances in optimal reliability allocation. IEEE Transactions Syst. Man Cybern. 37(1), 43-56.

Kurata, H., Nam, S., 2010. After-sales service competition in a supply chain: optimization of customer satisfaction level or profit or both? Int. J. Prod. Econ. 127(1), 136-146. doi:10.1016/j.ijpe.2010.05.005.

Kurata, H., Nam, S., 2013. After-sales service competition in a supply chain: Does uncertainty affect the conflict between profit maximization and customer satisfaction? Int. J. Prod. Econ. 144(1), 268280. doi:10.1016/j.ijpe.2013.02.014.

Lee, H.L., Rosenblatt, M.J., 1987. Simultaneous determination of production cycle and inspection schedules in a production system. Manag. Sci. 33(9), 1125-1136. doi:10.1287/mnsc.33.9.1125.

Li, G., Huang, F.F., Cheng, T.C.E., Zheng, Q., Ji, P., 2014. Make-or-buy service capacity decision in a supply chain providing after-sales service. Eur. J. Oper. Res. 239(2), 377-388. doi:10.1016/j.ejor.2014.05.035. 
Li, K., Mallik, S., Chhajed, D., 2012. Design of extended warranties in supply chains under additive demand. Prod. Oper. Manag., 2012. doi:10.1111/j.1937-5956.2011.01300.x.

Li, S., Li, Z.Z., 2012. Spare parts allocation by improved genetic algorithm and Monte Carlo simulation. Int. J. Syst. Sci. 43(6), 997-1006. doi:10.1080/00207720802556252.

Lieckens, K.T., Colen, P.J., Lambrecht, M.R., 2013. Optimization of a stochastic remanufacturing network with an exchange option. Decis. Support Syst. 54(4), 1548-1557. doi:10.1016/j.dss.2012.05.057.

Lin, P., Shue, L., 2005. Application of optimal control theory to product pricing and warranty with free replacement under the influence of basic lifetime distributions. Comput. Ind. Eng. 48(1), 69-82. doi:10.1016/j.cie.2004.07.009.

Majid, H.A., Wulandhari, L.A., Samah, A.A., Chin, A.J., 2012. A framework in determining extended warranty by using two dimensional delay time model. Adv. Mat. Res. 433-440, 2997-3002. doi:10.4028/www.scientific.net/AMR.433-440.2997.

Marseguerra, M., Zio, E., Podofillini, L., 2005. Multiobjective spare part allocation by means of genetic algorithms and Monte Carlo simulation. Reliab. Eng. Syst. Saf. 87(3), 325-335. doi:10.1016/j.ress.2004.06.002.

McAvoy, J., 2008. Integrating spare parts planning with logistics. Report, Aberdeen Group.

Menke, W.W., 1969. Determination of warranty reserves. Manag. Sci. 15(10), B-542-B-549. doi:10.1287/mnsc.15.10.B542.

Mohammaddust, F., Rezapour, S., Farahani, R.Z., Mofidfar, M., Hill, A., 2015. Developing lean and responsive supply chains: a robust model for alternative risk mitigation strategies in supply chain designs. Int. J. Prod. Econ. In Press. doi:10.1016/j.ijpe.2015.09.012.

Murthy, D.N.P., 1990. Optimal reliability choice in product design. Eng. Optimization 15(4), 281-294. doi:10.1080/03052159008941158. 
Nguyen, D.G., Murthy, D.N.P., 1984. A general model for estimating warranty costs for repairable products. IIE Transactions 16(4), 379-386. doi:10.1080/07408178408975258.

Nguyen, D.G., Murthy, D.N.P., 1988. Optimal reliability allocation for products sold under warranty. Eng. Optimization 13(1), 35-45. doi:10.1080/03052158808940945.

Niemi, P., Huiskonen, J., Kärkkäinen, H., 2009. Understanding the knowledge accumulation process implications for the adoption of inventory management techniques. Int. J. Prod. Econ. 118(1), 160-167. doi:10.1016/j.ijpe.2008.08.028.

Nissan, 2011. Warranty Information Booklet. https://owners.nissanusa.com/content/techpub/warranty/2011_N_WIB.pdf.

Nourelfath, M., Ait-Kadi, D., 2007. Optimization of series-parallel multi-state systems under maintenance policies. Reliab. Eng. Syst. Saf. 92(12), 1620-1626. doi:10.1016/j.ress.2006.09.016.

Öner, K.B., Kiesmüller, G.P., van Houtum, G.J., 2010. Optimization of component reliability in the design phase of capital goods. Eur. J. Oper. Res. 205(3), 615-624. doi:10.1016/j.ejor.2010.01.030.

Pan, F., Nagi, R., 2010. Robust supply chain design under uncertain demand in agile manufacturing. Comput. Oper. Res. 37(4), 668-683. doi:10.1016/j.cor.2009.06.017.

Park, S., Lee, T., Sung, C.S., 2010. A three-level supply chain network design model with risk-pooling and lead times. Transport. Res. E - Log. 46(5), 563-581. doi:10.1016/j.tre.2009.12.004.

Perlman, Y., Mehrez, A., Kaspi, M., 2001. Setting expediting repair policy in a multi-echelon repairableitem inventory system with limited repair capacity. J. Oper. Res. Soc. 52(2), 198-209. doi:10.1057/palgrave.jors.2601079.

Rappold, J.A., Van Roo, B.D., 2009. Designing multi-echelon service parts networks with finite repair capacity. Eur. J. Oper. Res. 199(3), 781-792. doi:10.1016/j.ejor.2008.08.006. 
Rezapour, S., 2011. Competition in supply chain. In: Farahani, R.Z., Rezapour, S., Kardar, L. (Eds.). Supply Chain Sustainability and Raw Material Management: Concepts and Processes, IGI Global, Hershey, USA, pp. 215-232.

Rezapour, S., Allen, J.K., Mistree, F., 2014a. Uncertainty propagation in a supply chain / network with uncertain facility performances. ASME International Design Engineering Technical Conferences, Buffalo, New York, August 2014. Paper Number DETC2014-34255.

Rezapour, S., Allen, J.K., Mistree, F., 2014b. Concurrent planning of forward and after-sale supply chains against demand and supply side uncertain. INFORMS Annual Meeting, San Francisco, USA.

Rezapour, S., Allen, J.K., Mistree, F., 2015a. Uncertainty propagation in a supply chain or supply network. Transport. Res. E - Log. 73, 185-206. doi:10.1016/j.tre.2014.10.010.

Rezapour, S., Allen, J.K., Mistree, F., 2015b. Stochastic supply networks servicing pre- and after-sales markets. ASME International Design Engineering Technical Conferences, Boston, Massachusetts, August 2015. Paper Number DETC2015-46749.

Rezapour, S., Allen, J.K., Trafalis, T.B., Mistree, F., 2013. Robust supply chain network design by considering demand-side uncertainty and supply-side disruption. ASME International Design Engineering Technical Conferences, Portland, Oregon, August 2013. Paper Number DETC201313188.

Rezapour, S., Farahani, R.Z., 2014. Supply chain network design under oligopolistic price and service level competition with foresight. Comput. Ind. Eng. 72, 129-142. doi:10.1016/j.cie.2014.03.005.

Romeijn, H.E., Shu, J., Teo, C., 2007. Designing two-echelon supply networks. Eur. J. Oper. Res. 178(2), 449-462. doi:10.1016/j.ejor.2006.02.016.

Rosenblatt, M.J., Lee, H.L., 1986. Economic production cycles with imperfect production processes. IIE Transactions 18(1), 48-55. doi:10.1080/07408178608975329. 
Sahba, P., Balciog lu, B., 2011. The impact of transportation delays on repairshop capacity pooling and spare part inventories. Eur. J. Oper. Res. 214(3), 674-682. doi:10.1016/j.ejor.2011.05.022.

Sana, S.S., 2010. An economic production lot size model in an imperfect production system. Eur. J. Oper. Res. 201(1), 158-170. doi:10.1016/j.ejor.2009.02.027.

Schütz, P., Tomasgard, A., Ahmed, S., 2009. Supply chain design under uncertainty using sample average approximation and dual decomposition. Eur. J. Oper. Res. 199(2), 409-419. doi:10.1016/j.ejor.2008.11.040.

Shen, Z., Qi, L., 2007. Incorporating inventory and routing costs in strategic location models. Eur. J. Oper. Res. 179(2), 372-389. doi:10.1016/j.ejor.2006.03.032.

Sherbrooke, C.C., 1968. Metric: A multi-echelon technique for recoverable item control. Oper. Res. 16(1), 122-141. doi:10.1287/opre.16.1.122.

Sheu, S., Chien, Y., 2005. Optimal burn-in time to minimize the cost for general repairable products sold under warranty. Eur. J. Oper. Res. 163(2), 445-461. doi:10.1016/j.ejor.2003.06.043.

Sleptchenko, A., van der Heijden, M.C., van Harten, A., 2002. Effects of finite repair capacity in multiechelon, multi-indenture service part supply systems. Int. J. Prod. Econ. 79(3), 209-230. doi:10.1016/S0925-5273(02)00155-X.

Su, C., Shen, J., 2012. Analysis of extended warranty policies with different repair options. Eng. Fail. Anal. 25, 49-62. doi:10.1016/j.engfailanal.2012.04.002.

van Ommeren, J.C.W., Bumb, A.F., Sleptchenko, A.V., 2006. Locating repair shops in a stochastic environment. Comput. Oper. Res. 33(6), 1575-1594. doi:10.1016/j.cor.2004.11.008.

Wagner, S.M., Lindemann, E., 2008. A case study-based analysis of spare parts management in the engineering industry. Prod. Plan. Contr. 19(4), 397-407. doi:10.1080/09537280802034554. 
Wang, L., Chu, J., Mao, W., 2009. A condition-based replacement and spare provisioning policy for deteriorating systems with uncertain deterioration to failure. Eur. J. Oper. Res. 194(1), 184-205. doi:10.1016/j.ejor.2007.12.012.

Wang, W., 2012. A stochastic model for joint spare parts inventory and planned maintenance optimisation. Eur. J. Oper. Res. 216(1), 127-139. doi:10.1016/j.ejor.2011.07.031.

Wei, J., Zhao, J., Li, Y., 2015. Price and warranty period decisions for complementary products with horizontal firms' cooperation/noncooperation strategies. J. Cleaner Prod. 105, 86-102. doi:10.1016/j.jclepro.2014.09.059.

Wu, C., Chou, C., Huang, C., 2009. Optimal price, warranty length and production rate for free replacement policy in the static demand market. Omega 37(1), 29- 39. doi:10.1016/j.omega.2006.07.005.

Wu, C., Lin, P., Chou, C., 2006. Determination of price and warranty length for a normal lifetime distributed product. Int. J. Prod. Econ. 102(1), 95-107. doi:10.1016/j.ijpe.2005.02.002.

Yeh, R.H., Chen, G.C., Chen, M.Y., 2005. Optimal age-replacement policy for nonrepairable products under renewing free-replacement warranty. IEEE Trans. Rel. 54(1), 92-97. doi:10.1109/TR.2004.841723.

You, F., Grossmann, I.E., 2008. Design of responsive supply chains under demand uncertainty. Comput. Chem. Eng. 32(12), 3090-3111. doi:10.1016/j.compchemeng.2008.05.004.

Zhou, Z., Li, Y., Tang, K., 2009. Dynamic pricing and warranty policies for products with fixed lifetime. Eur. J. Oper. Res. 196(3), 940-948. doi:10.1016/j.ejor.2008.04.014.

Zuo, M.J., Liu, B., Murthy, D.N.P., 2000. Replacement -repair policy for multi-state deteriorating products under warranty. Eur. J. Oper. Res. 123(3), 519-530. doi:10.1016/S0377-2217(99)001071. 


\section{Appendix A}

\section{Proof of Lemma 1:}

As explained before, the probability of the $j^{\text {th }}$ failure in the $[0, w]$ interval is equal to:

$$
\operatorname{Pr}\left\{\operatorname{Num}_{i}(w)=j\right\}=F_{i}^{(j)}\left(w, \lambda_{i}\right)-F_{i}^{(j+1)}\left(w, \lambda_{i}\right) \quad(\forall i=1,2, \ldots, r)
$$

Therefore, the average number of failures, $E_{i}\left(w, n_{i}\right)$, is computed as

$$
\begin{aligned}
E_{i}\left(w, n_{i}\right)= & \sum_{j=n_{i}+1}^{\infty} j \times \operatorname{Pr}\left\{\operatorname{Num}_{i}(w)=j\right\}=\sum_{j=n_{i}+1}^{\infty} j \times\left[F_{i}^{(j)}\left(w, \lambda_{i}\right)-F_{i}^{(j+1)}\left(w, \lambda_{i}\right)\right] \\
= & \left(n_{i}+1\right) \times\left[F_{i}^{\left(n_{i}+1\right)}\left(w, \lambda_{i}\right)-F_{i}^{\left(n_{i}+2\right)}\left(w, \lambda_{i}\right)\right]+ \\
& \left(n_{i}+2\right) \times\left[F_{i}^{\left(n_{i}+2\right)}\left(w, \lambda_{i}\right)-F_{i}^{\left(n_{i}+3\right)}\left(w, \lambda_{i}\right)\right]+ \\
& \left(n_{i}+3\right) \times\left[F_{i}^{\left(n_{i}+2\right)}\left(w, \lambda_{i}\right)-F_{i}^{\left(n_{i}+3\right)}\left(w, \lambda_{i}\right)\right]+\cdots \\
= & \left(n_{i}+1\right) \times F_{i}^{\left(n_{i}+1\right)}\left(w, \lambda_{i}\right)+F_{i}^{\left(n_{i}+2\right)}\left(w, \lambda_{i}\right)+F_{i}^{\left(n_{i}+3\right)}\left(w, \lambda_{i}\right)+\ldots \\
= & n_{i} \times F_{i}^{\left(n_{i}+1\right)}\left(w, \lambda_{i}\right)+\sum_{j=n_{i}+1}^{\infty} F_{i}^{(j)}\left(w, \lambda_{i}\right)
\end{aligned}
$$

\section{Proof of Lemma 2:}

The variance of the number of failures, $\sigma_{i}^{2}\left(w, n_{i}\right)$, is computed as 
$\sigma_{i}^{2}\left(w, n_{i}\right)=\sum_{j=n_{i}+1}^{\infty} j^{2} \times \operatorname{Pr}\left\{\operatorname{Num}_{i}(w)=j\right\}-\left[\sum_{j=n_{i}+1}^{\infty} j \times \operatorname{Pr}\left\{\operatorname{Num}_{i}(w)=j\right\}\right]^{2}$

The second term of (31) is already computed in Lemma 1 . Therefore, we first compute the first term of (31):

$$
\begin{aligned}
& \sum_{j=n_{i}+1}^{\infty} j^{2} \times \operatorname{Pr}\left\{\operatorname{Num}_{i}(w)=j\right\}=\left(n_{i}+1\right)^{2} \times\left[F_{i}^{\left(n_{i}+1\right)}\left(w, \lambda_{i}\right)-F_{i}^{\left(n_{i}+2\right)}\left(w, \lambda_{i}\right)\right]+ \\
& \left(n_{i}+2\right)^{2} \times\left[F_{i}^{\left(n_{i}+2\right)}\left(w, \lambda_{i}\right)-F_{i}^{\left(n_{i}+3\right)}\left(w, \lambda_{i}\right)\right]+ \\
& \left(n_{i}+3\right)^{2} \times\left[F_{i}^{\left(n_{i}+3\right)}\left(w, \lambda_{i}\right)-F_{i}^{\left(n_{i}+4\right)}\left(w, \lambda_{i}\right)\right]+\cdots \\
& =\left(n_{i}+1\right)^{2} \times F_{i}^{\left(n_{i}+1\right)}\left(w, \lambda_{i}\right)+\left(3+2 n_{i}\right) \cdot F_{i}^{\left(n_{i}+2\right)}\left(w, \lambda_{i}\right)+\left(5+2 n_{i}\right) \cdot F_{i}^{\left(n_{i}+3\right)}\left(w, \lambda_{i}\right)+\cdots \\
& =\left(n_{i}+1\right)^{2} \times F_{i}^{\left(n_{i}+1\right)}\left(w, \lambda_{i}\right)+\sum_{j=n_{i}+2}^{\infty}(2 j-1) \cdot F_{i}^{(j)}\left(w, \lambda_{i}\right)
\end{aligned}
$$

By substituting Equations (32) and (30) into Equation (31), $\sigma_{i}^{2}\left(w, n_{i}\right)$ is simplified as

$$
\begin{gathered}
\sigma_{i}^{2}\left(w, n_{i}\right)=\left(n_{i}+1\right)^{2} \times F_{i}^{\left(n_{i}+1\right)}\left(w, \lambda_{i}\right)+\sum_{j=n_{i}+2}^{\infty}(2 j-1) \cdot F_{i}^{(j)}\left(w, \lambda_{i}\right)-\left[n_{i} \times F_{i}^{\left(n_{i}+1\right)}\left(w, \lambda_{i}\right)+\right. \\
\left.\sum_{j=n_{i}+1}^{\infty} F_{i}^{(j)}\left(w, \lambda_{i}\right)\right]^{2}
\end{gathered}
$$

\section{Appendix B}

Here, we attempt to elaborate on why $w$ is considered in the after-sales demand prediction. We assume that the warranty length is an integer multiple of the sales period: $w=k_{1} . T$. In the sales period, $T$, we define $\tilde{T}$ as the longest time period in which it is logical to assume that the product demand occurs at the beginning of the period. Again, the sales period is an integer multiple of $\overleftarrow{T}: T=k_{2} \cdot \dot{T}$. If we assume that the rate of the product demand is nearly constant, then the product sales quantity in each period $\bar{T}$ is ${ }^{x} / k_{2}$. 
We define $D r_{i j}\left(\forall i=1,2, \ldots, r\right.$ and $\left.\forall j=1,2, \ldots, k_{1}, k_{2}\right)$ as the required quantity of Component $i$ to repair the returned products in batch ${ }^{x} / k_{2}$ sold in the $j^{\text {th }}$ period of $\tilde{T}$. Consider an example production system in which $w=3 T$ and $T=4 \hat{T}$. Figure 8 shows the required amount of Component $i$ in the interval $[0, \tilde{T}]$ for the ${ }^{x} / k_{2}$ product batch sold in that interval and all of the product batches already sold and their warranty times if they have not yet been completed. As seen in Figure 8 , this total quantity is equal to $\sum_{j=1}^{k_{1}, k_{2}} D r_{i j}$, which is equal to the required quantity of Component $i$ for $\mathrm{a}^{x} / k_{2}$ product batch inside the warranty time, $w=k_{1}, k_{2}, \hat{T}$. The same quantity of Component $i$ is required for intervals $[\check{T}, \tilde{2 T}],[\tilde{2 T}, \hat{3 T}], \ldots$ $\left[\left(k_{2}-1\right) \hat{T}, k_{2} \tilde{T}\right]$ inside the sale period. Therefore, a quantity of $k_{2} \cdot \sum_{j=1}^{k_{1} \cdot k_{2}} D r_{i j}$ of Component $i$ is required inside the sale period, which is equal to the required quantity of Component $i$ for $\left(x / k_{2} \cdot k_{2}=x\right)$ product units inside the warranty time, $w$.

Figure B1 goes about here.

\section{Appendix C}

The linearized mathematical model is.

\section{$\operatorname{Max}$}

$$
\begin{gathered}
\Pi=\sum_{i=1}^{|R L 1|} \sum_{j=1}^{|R L 2|} \sum_{k=1}^{|R L 3|} \sum_{t=1}^{|W|} v_{r l 1^{i} r l 2^{i}, r l 3^{k} w^{t}} \times\left[\left(p-h^{+} \cdot E\left[G^{-1}\left(\operatorname{Max}\left\{r l 1^{i}, \frac{h^{-}}{h^{-}+h^{+}}\right\}\right)-\quad \varepsilon\right]^{+}-\right.\right. \\
\left.\left.h^{-} \cdot E\left[\varepsilon-G^{-1}\left(\operatorname{Max}\left\{r l 1^{i}, \frac{h^{-}}{h^{-}+h^{+}}\right\}\right)\right]^{+}-c r\right) \cdot D\left(p, r l 1^{i} \cdot r l 2^{j} \cdot\left(r l 3^{k}\right)^{r},\left(r l 1^{i} \cdot r l 3^{k}\right)^{r}, w^{t}\right)\right]- \\
{\left[\sum_{i=1}^{r}\left(a_{1 i}+a_{2 i}\right) \cdot\left(x+\Delta x+x_{i}+\Delta \hat{x}_{i}\right)+\sum_{i=1}^{r} \frac{h_{1 i} \cdot\left(x+\Delta x+x_{i}\right)^{2}}{2 \cdot P R_{1 i}}+\sum_{i=1}^{r} b_{1 i} \cdot(x+\Delta x)+\right.} \\
\left.b_{2} \cdot(x+\Delta x)+\frac{h_{2} \cdot(x)^{2}}{2 \cdot P R_{2}}+\left(c_{1}+c_{2}\right) \cdot x+\sum_{i=1}^{r} c_{3 i} \cdot x_{i}\right]
\end{gathered}
$$

\section{Subject to}

$$
\begin{aligned}
x= & \sum_{i=1}^{|R L 1|} \sum_{j=1}^{|R L 2|} \sum_{k=1}^{|R L 3|} \sum_{t=1}^{|W|} v_{r l 1_{1}^{i} r l 2^{j}, r l 3^{k}{ }^{k} W^{t} \times} \\
& {\left[D\left(p, r l 1^{i}, r l 2^{j} \cdot\left(r l 3^{k}\right)^{r},\left(r l 1^{i}, r l 3^{k}\right)^{r}, W^{t}\right) \cdot G^{-1}\left(\operatorname{Max}\left\{r l 1^{i}, \frac{h^{-}}{h^{-}+h^{+}}\right\}\right)\right] }
\end{aligned}
$$




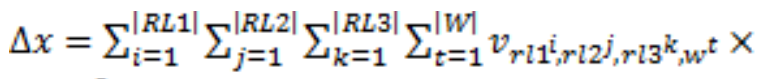

$$
\begin{aligned}
& {\left[D\left(p, r l 1^{i} \cdot r l 2^{j} \cdot\left(r l 3^{k}\right)^{r},\left(r l 1^{i}, r l 3^{k}\right)^{r}, w^{t}\right) \cdot G^{-1}\left(\operatorname{Max}\left\{r l 1^{i}, \frac{h^{-}}{h^{-}+h^{+}}\right\}\right) \cdot G^{r^{-1}}\left(r l 2^{j}\right)\right]}
\end{aligned}
$$

$$
\begin{aligned}
& x_{i}= \sum_{i=1}^{|R L 1|} \sum_{j=1}^{|R L 2|} \sum_{k=1}^{|R L 3|} \sum_{t=1}^{|W|} v_{r l 1^{i}, r l 2^{j}, r l 3^{k}{ }^{k} w^{t} \times} \\
& {\left[\left(D\left(p, r l 1^{i}, r l 2^{j} \cdot\left(r l 3^{k}\right)^{r},\left(r l 1^{i}, r l 3^{k}\right)^{r}, w^{t}\right) \cdot G^{-1}\left(\operatorname{Max}\left\{r l 1^{i}, \frac{h^{-}}{h^{-}+h^{+}}\right\}\right) \cdot E_{i}\left(w^{t}, n_{i}\right)\right)+\right.} \\
&\left.\left(z_{r l 1^{i}} \sqrt{D\left(p, r l 1^{i}, r l 2^{j} \cdot\left(r l 3^{k}\right)^{r},\left(r l 1^{i}, r l 3^{k}\right)^{r}, w^{t}\right) \cdot G^{-1}\left(\operatorname{Max}\left\{r l 1^{i}, \frac{h^{-}}{h^{-}+h^{+}}\right\}\right) \cdot \sigma_{i}^{2}\left(w^{t}, n_{i}\right)}\right)\right] \\
&(\forall i=1,2, \ldots, r)
\end{aligned}
$$

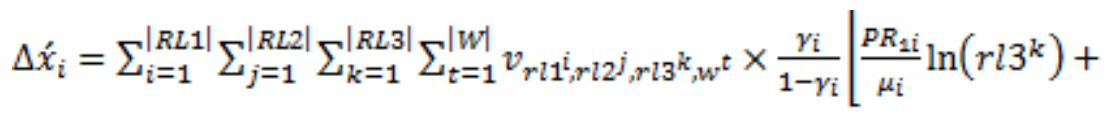

$$
\begin{aligned}
& D\left(p, r l 1^{i} \cdot r l 2^{j} \cdot\left(r l 3^{k}\right)^{r},\left(r l 1^{i} \cdot r l 3^{k}\right)^{r}, w^{t}\right) \cdot G^{-1}\left(\operatorname{Max}\left\{r l 1^{i}, \frac{h^{-}}{h^{-}+h^{+}}\right\}\right) \cdot\left(1+G^{v^{-1}}\left(r l 2^{j}\right)+\right. \\
& \left.E_{i}\left(w^{t}, n_{i}\right)\right)+ \\
& \left.z_{r l 1^{i}} \sqrt{D\left(p, r l 1^{i} \cdot r l 2^{j} \cdot\left(r l 3^{k}\right)^{r},\left(r l 1^{i} \cdot r l 3^{k}\right)^{r}, w^{t}\right) \cdot G^{-1}\left(\operatorname{Max}\left\{r l 1^{i}, \frac{h^{-}}{h^{-}+h^{+}}\right\}\right) \cdot \sigma_{i}^{2}\left(w^{t}, n_{i}\right)}\right] \\
& (\forall i=1,2, \ldots, r) \\
& \sum_{i=1}^{\| R L 1 \mid} y_{r I 1^{i}}=1 \\
& \left(\forall r l 1^{i} \in R L 1\right) \\
& \sum_{i=1}^{\|R L 2\|} y_{r L 2^{i}}=1 \\
& \left(\forall r l 2^{i} \in R L 2\right) \\
& \sum_{i=1}^{\|R L 3\|} y_{r l 3^{i}}=1 \\
& \left(\forall r l 3^{i} \in R L 3\right) \\
& \sum_{i=1}^{|W|} z_{w^{i}}=1 \\
& \left(\forall w^{t} \in W\right)
\end{aligned}
$$

$\left(\forall w^{t} \in W, \forall r l 1^{i} \in R L 1, \forall r l 2^{i} \in R L 2\right.$, and $\left.\forall r l 3^{i} \in R L 3\right)$

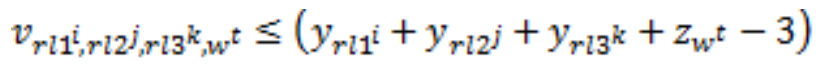

$\left(\forall w^{t} \in W, \forall r l 1^{i} \in R L 1, \forall r l 2^{i} \in R L 2\right.$, and $\left.\forall r l 3^{i} \in R L 3\right)$

$r l 1^{i}, r l 2^{j}, r l 3^{k}, w^{t}$, and,$v_{r l 1^{i}}^{i} r l 2^{j}{ }_{2} r l 3^{k}{ }^{k} w^{t} \in\{0,1\}$

$\left(\forall w^{t} \in W, \forall r l 1^{i} \in R L 1, \forall r l 2^{i} \in R L 2\right.$, and $\left.\forall r l 3^{i} \in R L 3\right)$ 


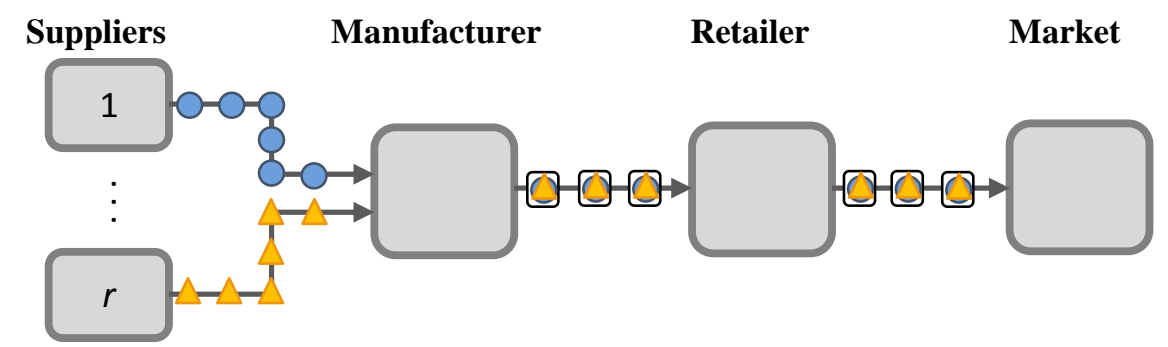

Figure 1. Network structure and flow dynamics through the forward SC 


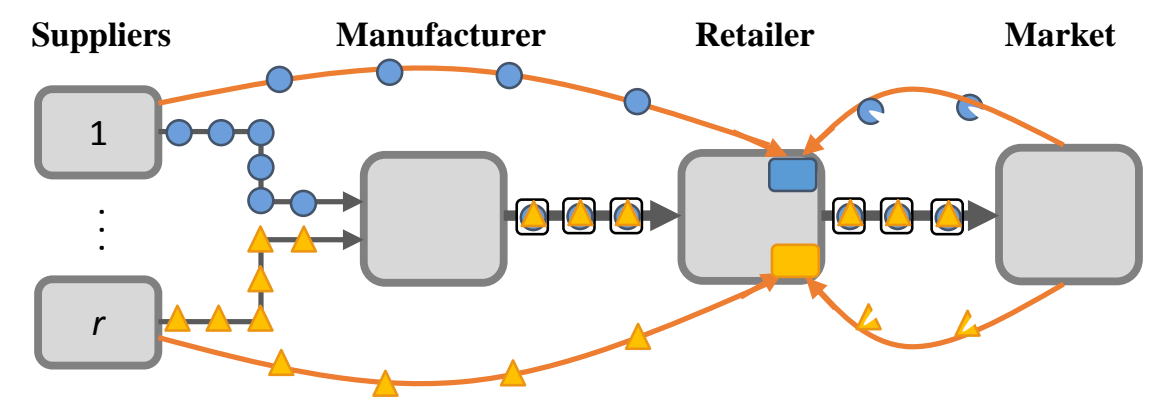

Figure 2. Network structure and flow dynamics through the after-sales SC. 


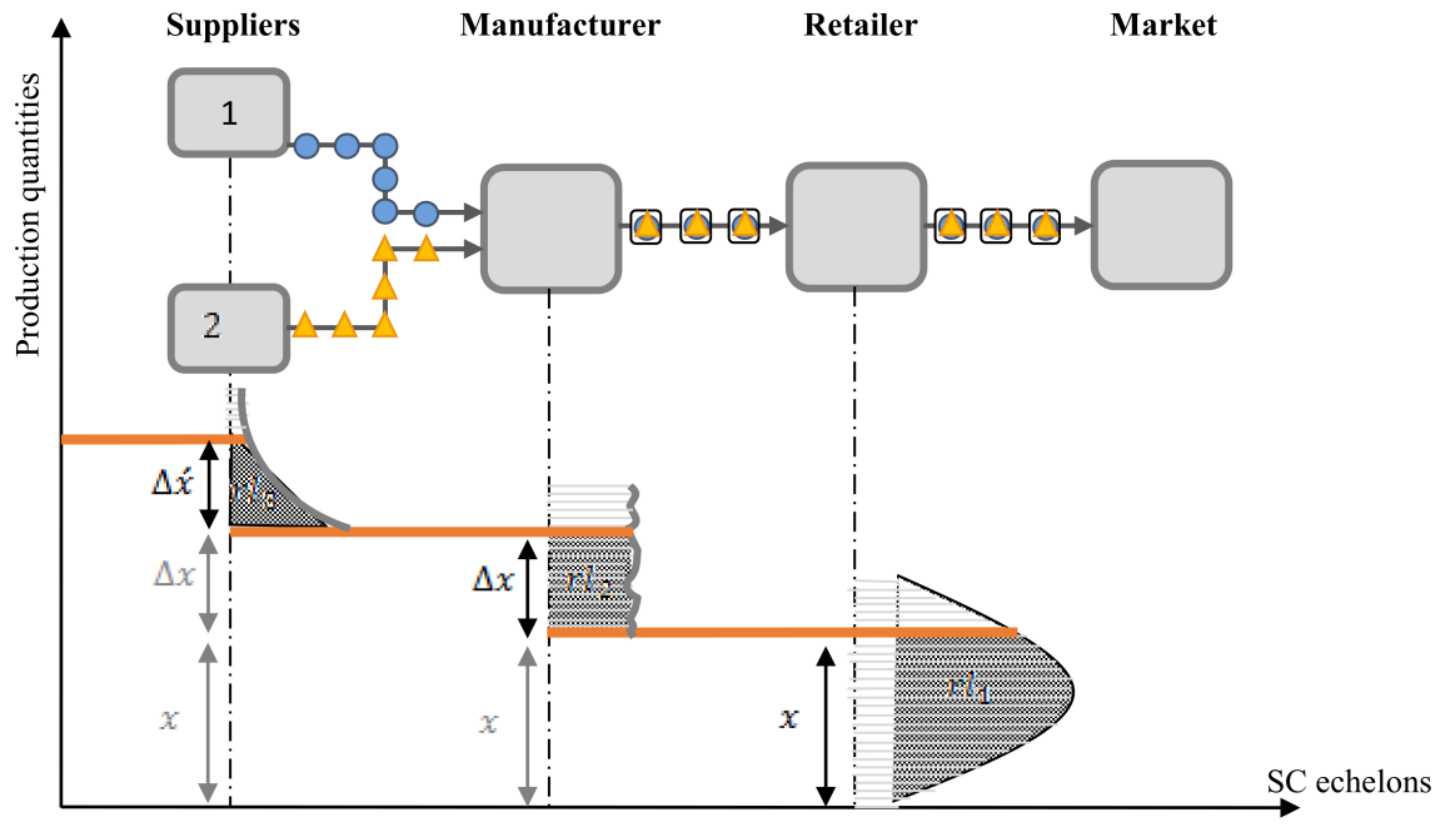

Figure 3. Qualified flow depreciation in the forward SC. 


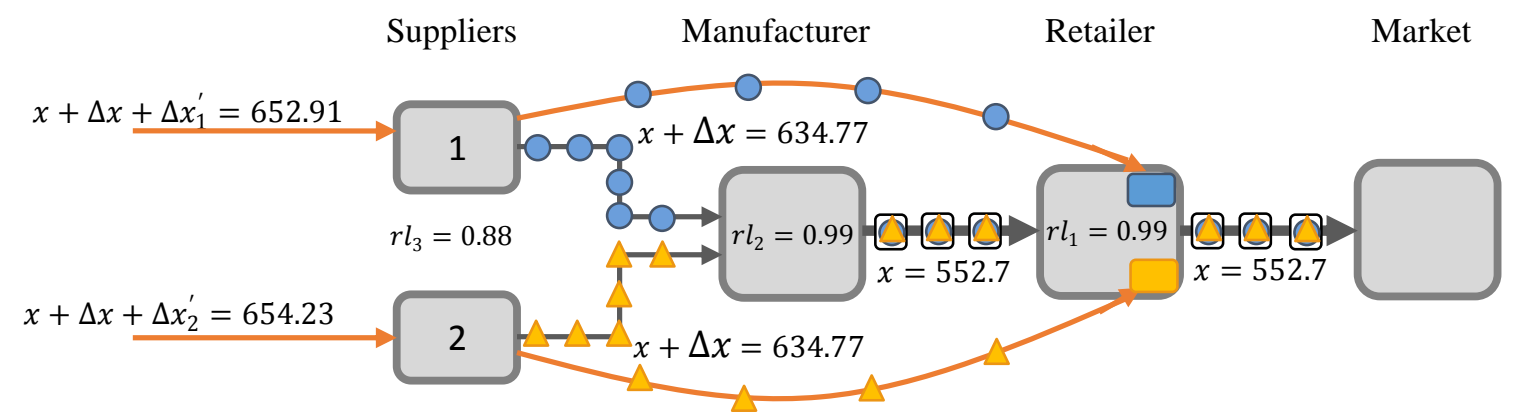

Figure 4. Flow dynamics in the SC. 


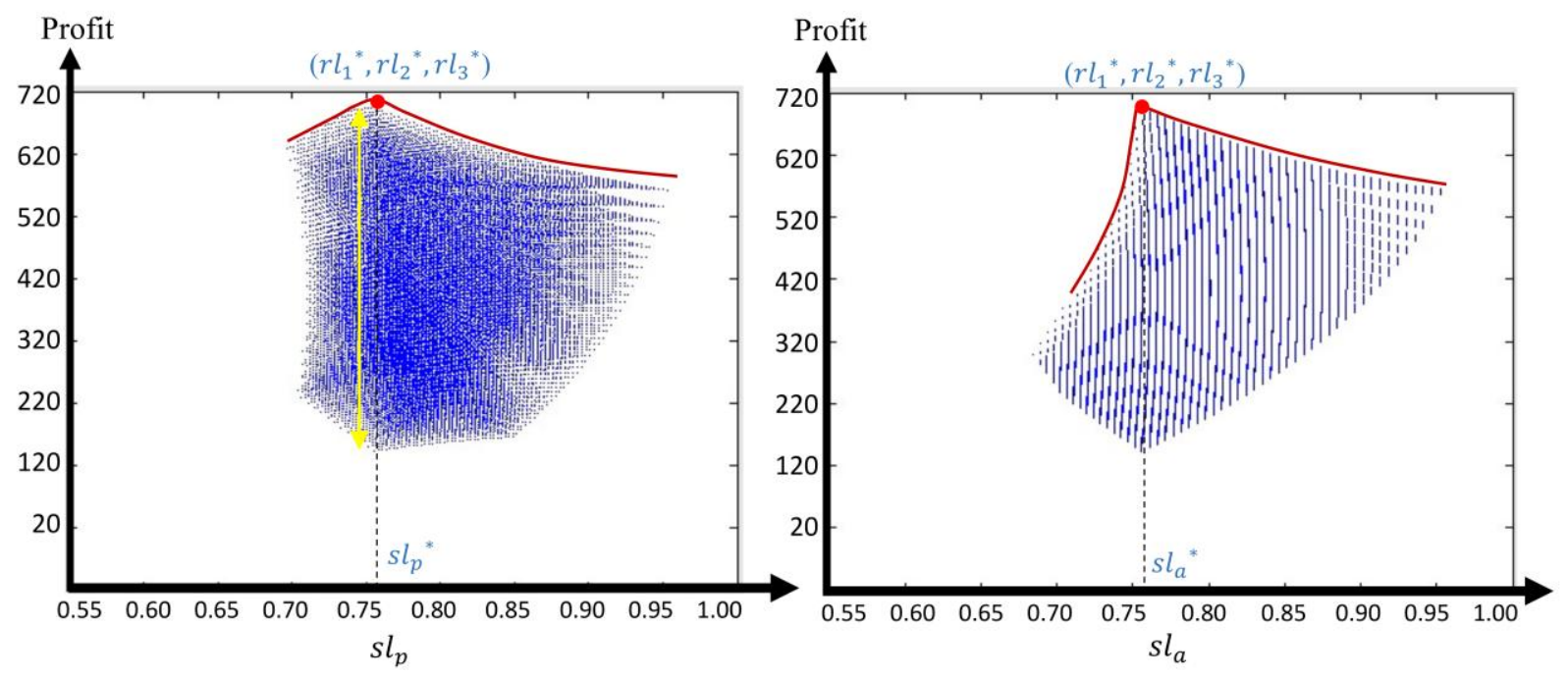

Figure 5. Profit with respect to the premarket service level.

Figure 6. Profit with respect to the after-sales service level. 


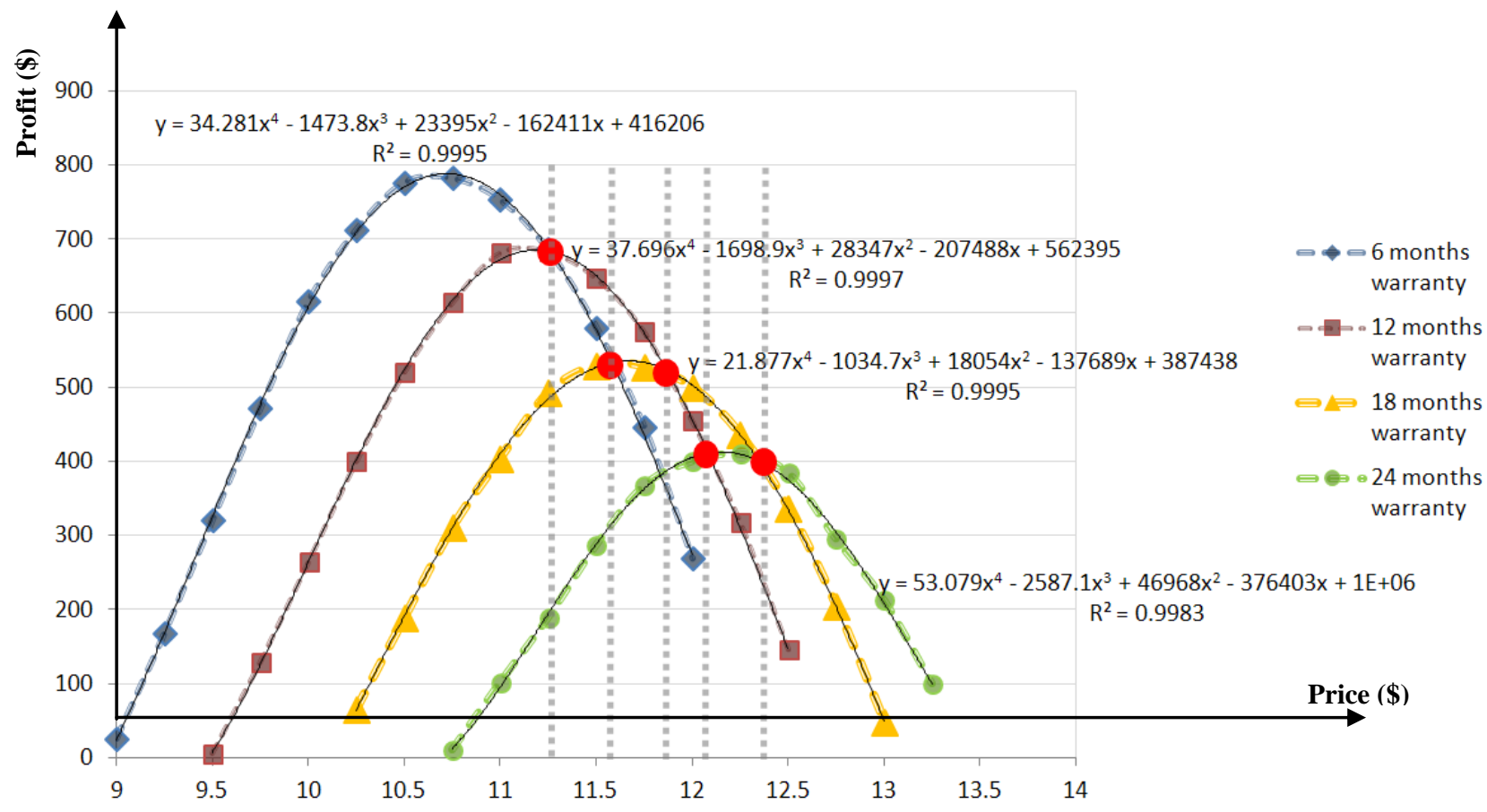

Figure 7. Profit of the company with respect to the retail price for different warranty lengths. 


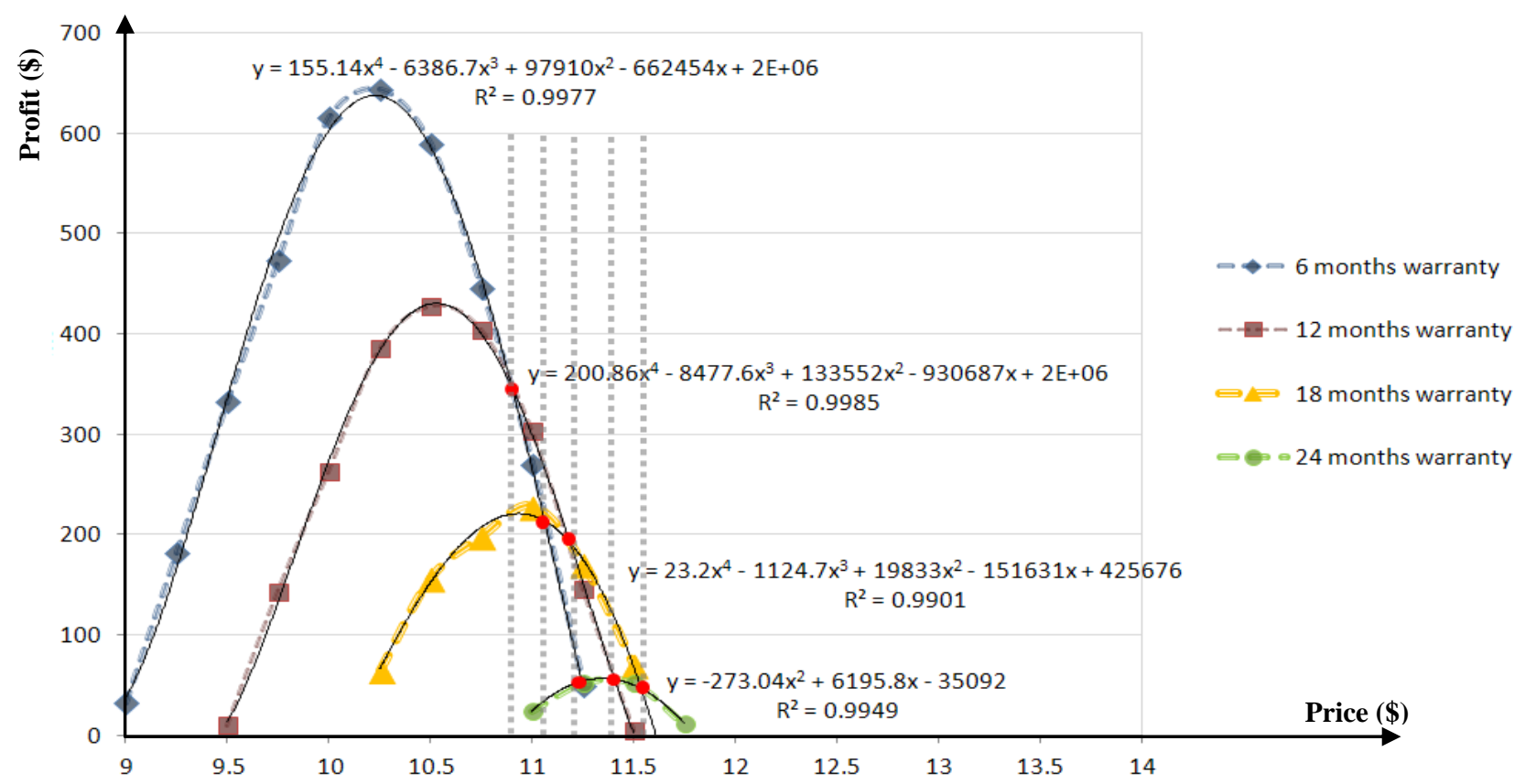

Figure 8. Profit of the company with respect to the retail price in price-sensitive markets. 


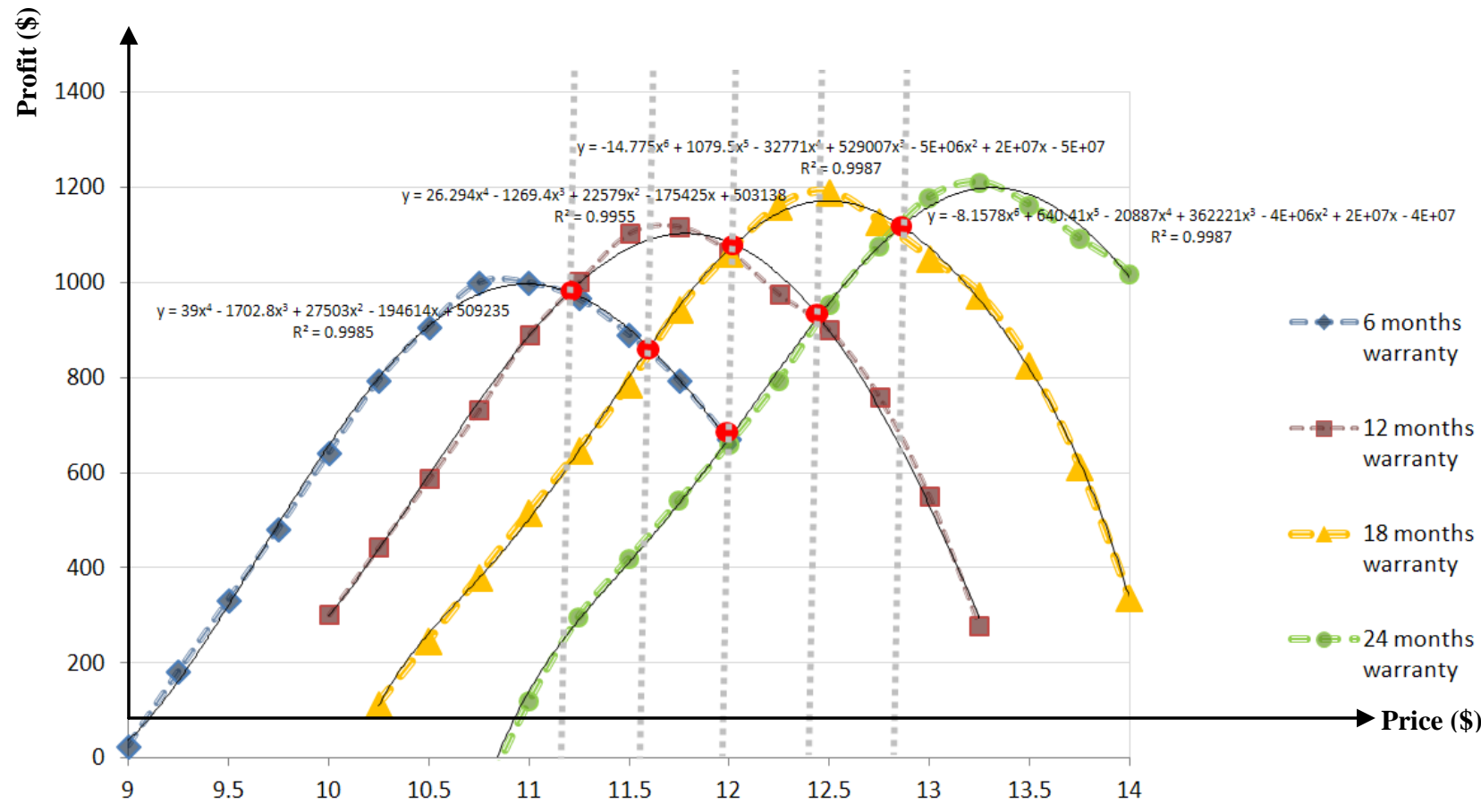

Figure 9. Profit of the company with respect to the retail price in warranty-sensitive markets. 


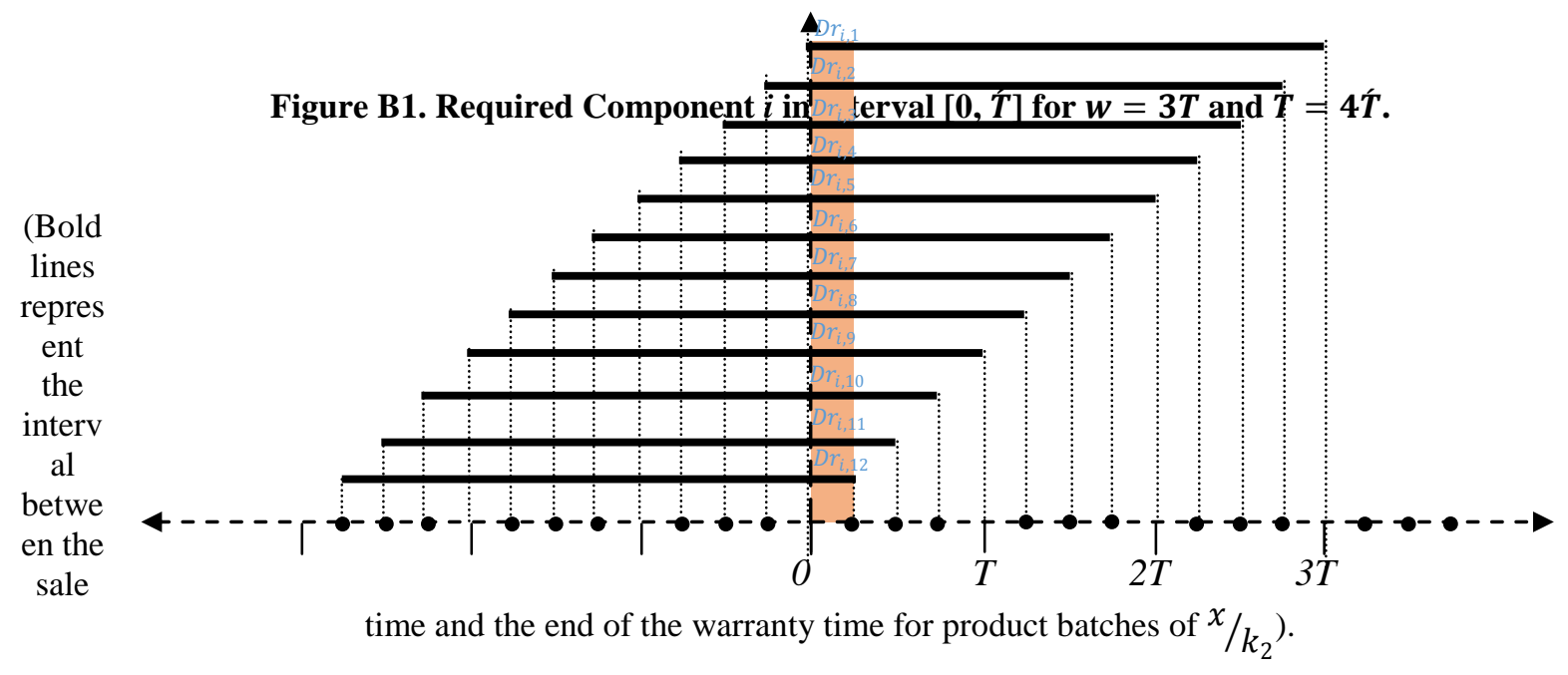




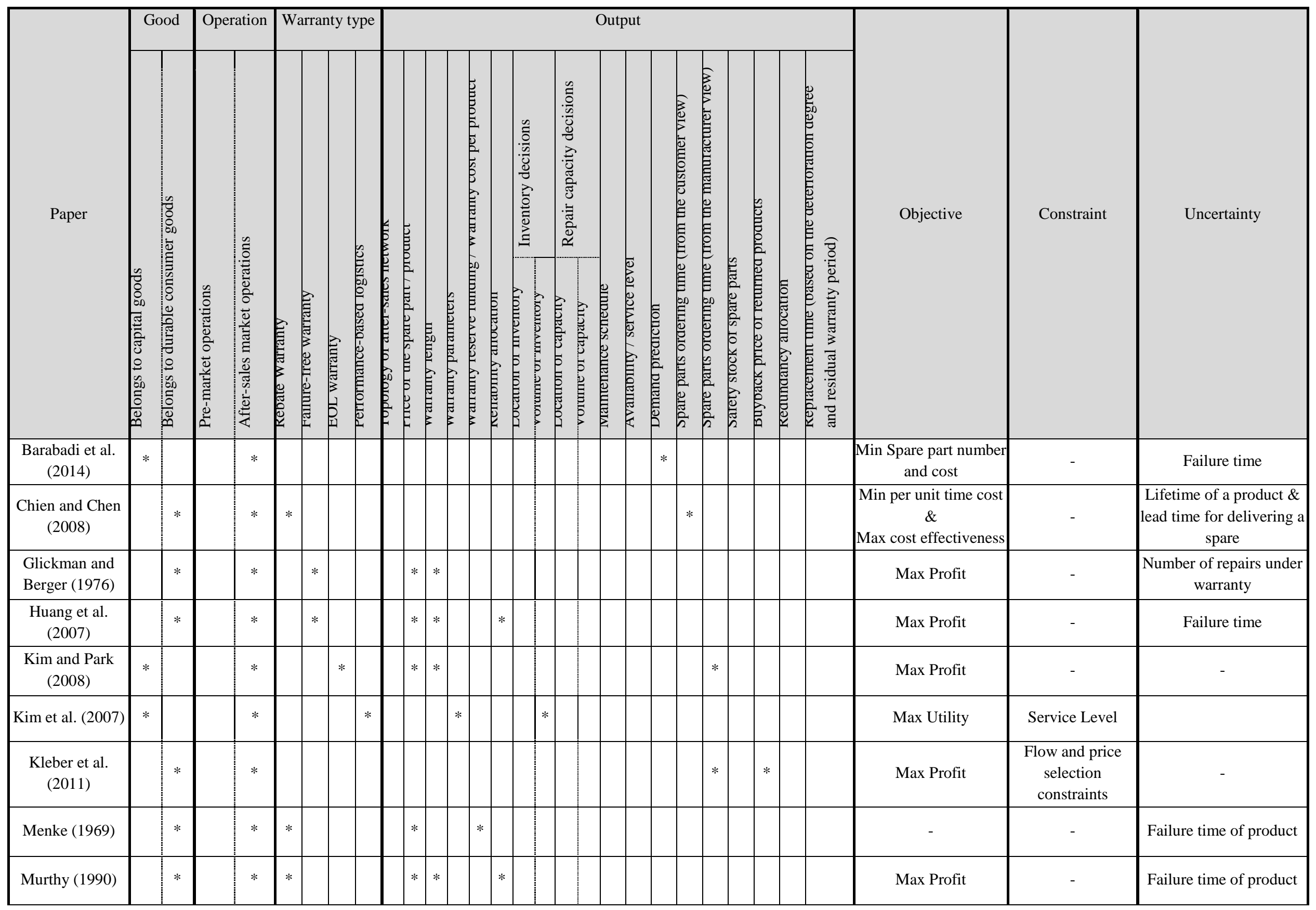




\begin{tabular}{|c|c|c|c|c|c|c|c|c|c|c|c|c|c|c|c|c|c|c|c|c|c|c|c|}
\hline \multirow[b]{2}{*}{ Paper } & \multicolumn{2}{|c|}{ Good } & \multicolumn{2}{|c|}{ Operation } & \multicolumn{4}{|c|}{ Warranty type } & \multicolumn{12}{|c|}{ Decision } & \multirow[b]{2}{*}{ Objective } & \multirow[b]{2}{*}{ Constraint } & \multirow[b]{2}{*}{ Uncertainty } \\
\hline & 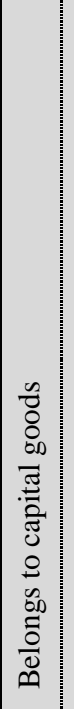 & 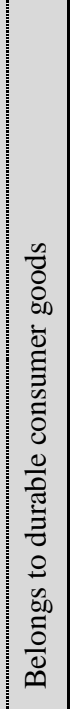 & 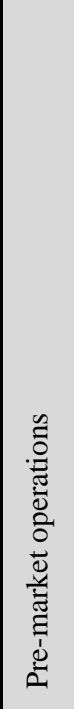 & 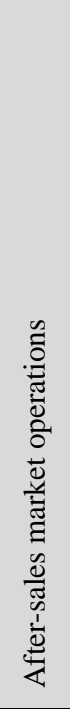 & 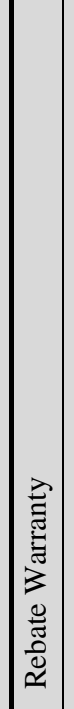 & 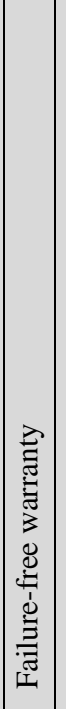 & 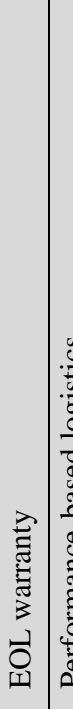 & 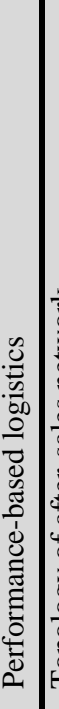 & 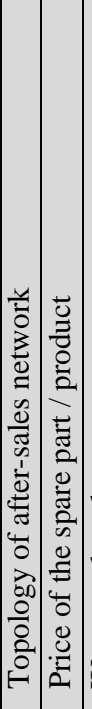 & 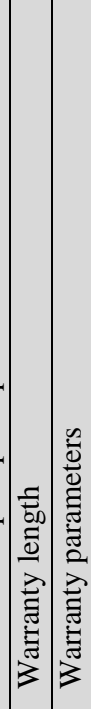 & 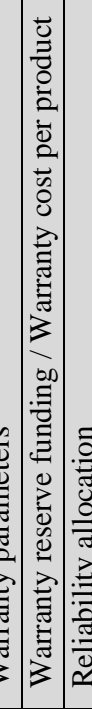 & 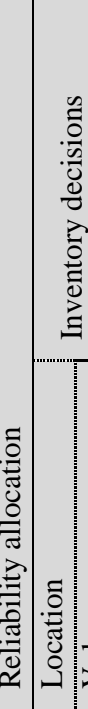 & 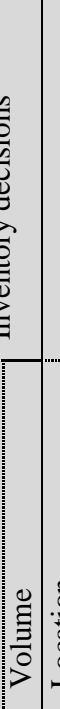 & 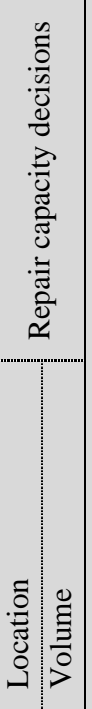 & 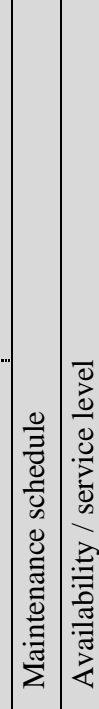 & 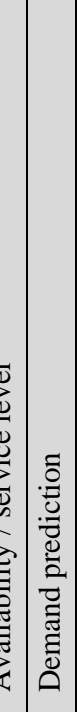 & 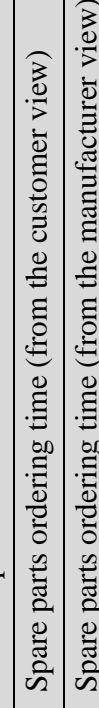 & 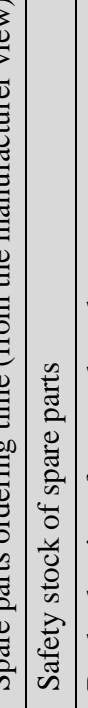 & 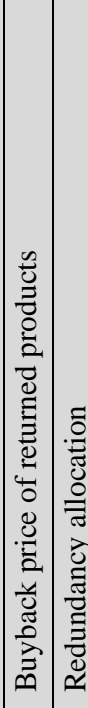 & 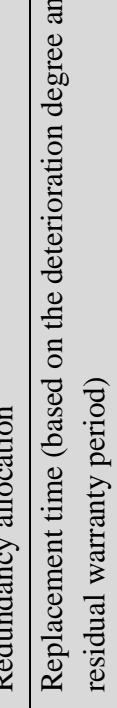 & & & \\
\hline $\begin{array}{l}\text { Nguyen and } \\
\text { Murthy (1984) }\end{array}$ & & * & & $*$ & & * & & & & & * & & & & & & & & & & - & - & Failure time of product \\
\hline $\begin{array}{l}\text { Nguyen and } \\
\text { Murthy (1988) }\end{array}$ & & $*$ & & * & $*$ & * & & & & & & * & & & & & & & & & $\begin{array}{c}\text { Min manufacturing + } \\
\text { servicing costs }\end{array}$ & - & Failure time of product \\
\hline Oner et al. (2010) & $*$ & & & $*$ & & & & $*$ & & & & * & $*$ & & & & & & & & Min cost & $\begin{array}{c}\text { Reliability } \\
\text { boundary }\end{array}$ & Failure and repair time \\
\hline \begin{tabular}{|c|} 
Sahba and \\
Balcioglu (2011) \\
\end{tabular} & $*$ & & & $*$ & & & & $*$ & $*$ & & & & $*$ & & & & & & & & Min cost & - & Failure and repair time \\
\hline Wang (2012) & $*$ & & & $*$ & & & & & & & & & $*$ & & $*$ & & & & & & $\begin{array}{l}\text { Min inventory }+ \text { shut } \\
\text { down costs }\end{array}$ & - & Plant failure \\
\hline $\begin{array}{l}\text { Wang et al. } \\
\text { (2009) }\end{array}$ & $*$ & & & $*$ & & & & & & & & & $*$ & & $*$ & & & & & & Min cost & - & $\begin{array}{c}\text { Uncertain deterioration } \\
\text { of each unit }\end{array}$ \\
\hline Anderson (1977) & & $*$ & & $*$ & & $*$ & & & $*$ & $*$ & & & & & & & & & & & Max Profit & $\begin{array}{l}\text { Price is more than } \\
\text { manufacturing cost }\end{array}$ & Failure time \\
\hline $\begin{array}{c}\text { Díaz and Fu } \\
(1997)\end{array}$ & $*$ & & & * & & & & & & & & & * & & & & & & & & - & Service level & Failure rate \& repair time \\
\hline Graves (1985) & $*$ & & & * & & & & & & & & & $*$ & & & & & & & & - & Service level & Failure rate \& repair time \\
\hline $\begin{array}{c}\text { Sherbrooke } \\
(1968)\end{array}$ & $*$ & & & $*$ & & & & & & & & & $*$ & & & & & & & & - & Service level & Failure rate \& repair time \\
\hline
\end{tabular}




\begin{tabular}{|c|c|c|c|c|c|c|c|c|c|c|c|c|c|c|c|c|c|c|c|c|c|c|c|c|c|c|c|c|}
\hline \multirow[b]{2}{*}{ Paper } & \multicolumn{2}{|c|}{ Good } & \multicolumn{2}{|c|}{ Operation } & \multicolumn{4}{|c|}{ Warranty type } & \multicolumn{17}{|c|}{ Decision } & \multirow[b]{2}{*}{ Objective } & \multirow[b]{2}{*}{ Constraint } & \multirow[b]{2}{*}{ Uncertainty } \\
\hline & 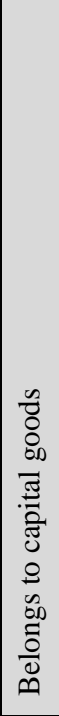 & 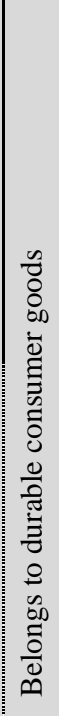 & 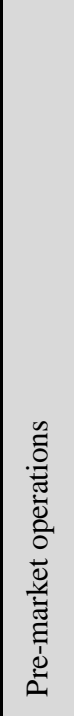 & 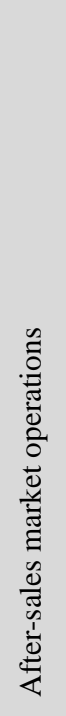 & 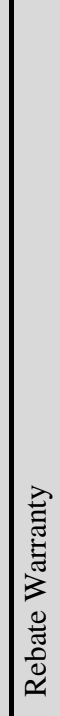 & 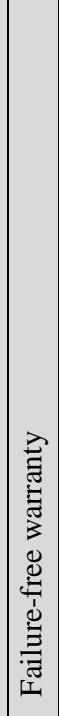 & 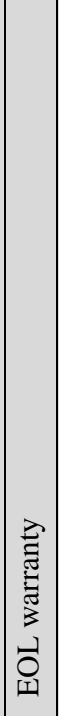 & 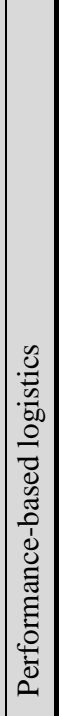 & 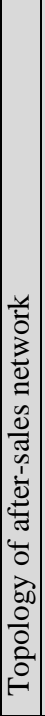 & 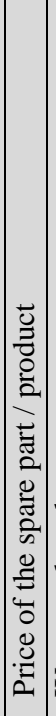 & 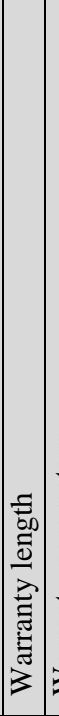 & 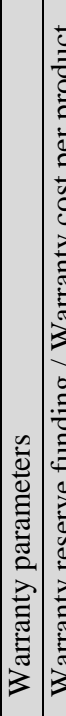 & 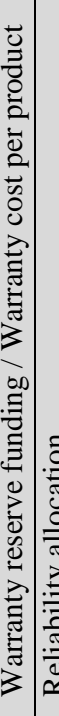 & & 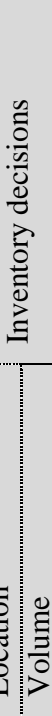 & o. & 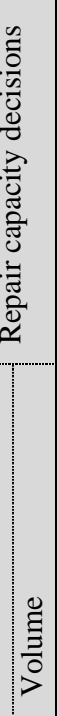 & 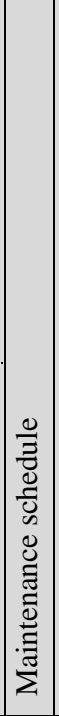 & 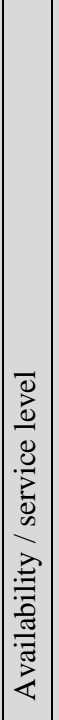 & 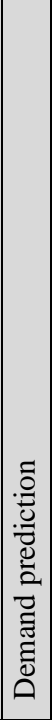 & 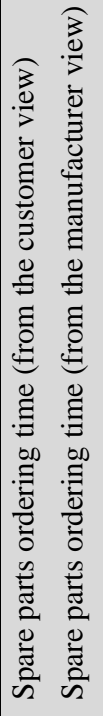 & 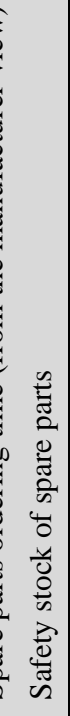 & 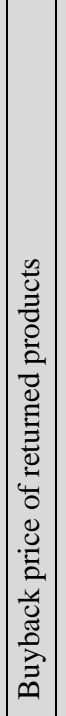 & 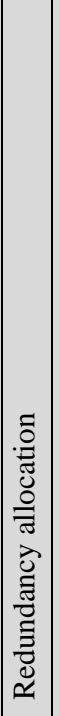 & 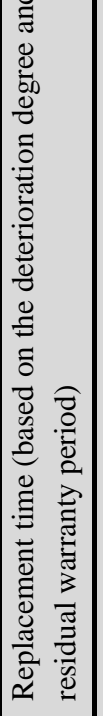 & & & \\
\hline $\begin{array}{l}\text { Perlman et al. } \\
\quad(2001)\end{array}$ & $*$ & & & $*$ & & & & & & & & & & & & & & & & & & $*$ & & & & Min sum of backorders & - & Failure rate \& repair time \\
\hline \begin{tabular}{|c|} 
Sleptchenko et al. \\
$(2002)$
\end{tabular} & $*$ & & & $*$ & & & & & & & & & & * & $*$ & & & & & & & & & & & Max Availability & - & Failure rate \& repair time \\
\hline \begin{tabular}{|c|} 
Hussain and \\
Murthy (2003) \\
\end{tabular} & & $*$ & & $*$ & & $*$ & & & & & & & * & 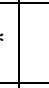 & & & & & & & & & & & & $\begin{array}{c}\text { Min manufacturing }+ \\
\text { warranty cost }\end{array}$ & - & $\begin{array}{c}\text { Failure rate \& reliability } \\
\text { improvement of parts }\end{array}$ \\
\hline $\begin{array}{l}\text { Hussain and } \\
\text { Murthy (2000) }\end{array}$ & & $*$ & & $*$ & & $*$ & & & & & & & & & & & & & & & & & & $*$ & & $\begin{array}{c}\text { Min manufacturing }+ \\
\text { warranty cost }\end{array}$ & - & $\begin{array}{c}\text { Failure rate \& reliability } \\
\text { of parts }\end{array}$ \\
\hline Zuo et al. (2000) & & $*$ & & $*$ & & $*$ & & & & & & & & & & & & & & & & & & & $*$ & Min warranty cost & - & $\begin{array}{c}\text { Failure \& deterioration } \\
\text { rate of parts }\end{array}$ \\
\hline $\begin{array}{l}\text { Lieckens et al. } \\
(2013)\end{array}$ & $*$ & & & $*$ & & & & $*$ & $*$ & & & & & * & $*$ & $*$ & $*$ & & & & $*$ & $*$ & & & & Max Profit & Service level & $\begin{array}{c}\text { Failure rate \& processing } \\
\text { time }\end{array}$ \\
\hline $\begin{array}{c}\text { Lin and Shue } \\
(2005)\end{array}$ & & $*$ & & $*$ & & $*$ & & & & $*$ & $*$ & & & & & & & & & & & & & & & Max Profit & - & Failure rate \\
\hline \begin{tabular}{|c|}
$\begin{array}{c}\text { Van Ommeren et } \\
\text { al. (2006) }\end{array}$ \\
\end{tabular} & & $*$ & & $*$ & & & & & $*$ & & & & & & * & $*$ & $*$ & & & & & & & & & $\begin{array}{c}\text { Min total expected } \\
\text { cost }\end{array}$ & Service level & $\begin{array}{c}\text { Demands and repair } \\
\text { times }\end{array}$ \\
\hline \begin{tabular}{|c|} 
Rappold and Roo \\
$(2009)$
\end{tabular} & & $*$ & & $*$ & & & & & $*$ & & & & & & $*$ & $*$ & $*$ & & & & & & & & & $\begin{array}{c}\text { Min total expected } \\
\text { cost }\end{array}$ & - & $\begin{array}{c}\text { Demands and repair } \\
\text { times }\end{array}$ \\
\hline \begin{tabular}{|c|} 
Gross and Pinkus \\
$(1979)$
\end{tabular} & $*$ & & & $*$ & & & & & $*$ & & & & & * & $*$ & $*$ & $*$ & & & & & & & & & $\begin{array}{c}\text { Min total expected } \\
\text { cost }\end{array}$ & Service level & $\begin{array}{c}\text { Failure rates and repair } \\
\text { times }\end{array}$ \\
\hline Chen et al. (2012) & & $*$ & & $*$ & & $*$ & & & & $* 1$ & $*^{2}$ & & & & & & & & & & & & & & & Max Profit & - & - \\
\hline
\end{tabular}

${ }^{1}$ Wholesale price of the manufacturer.

${ }^{2}$ Warranty length of the retailer. 


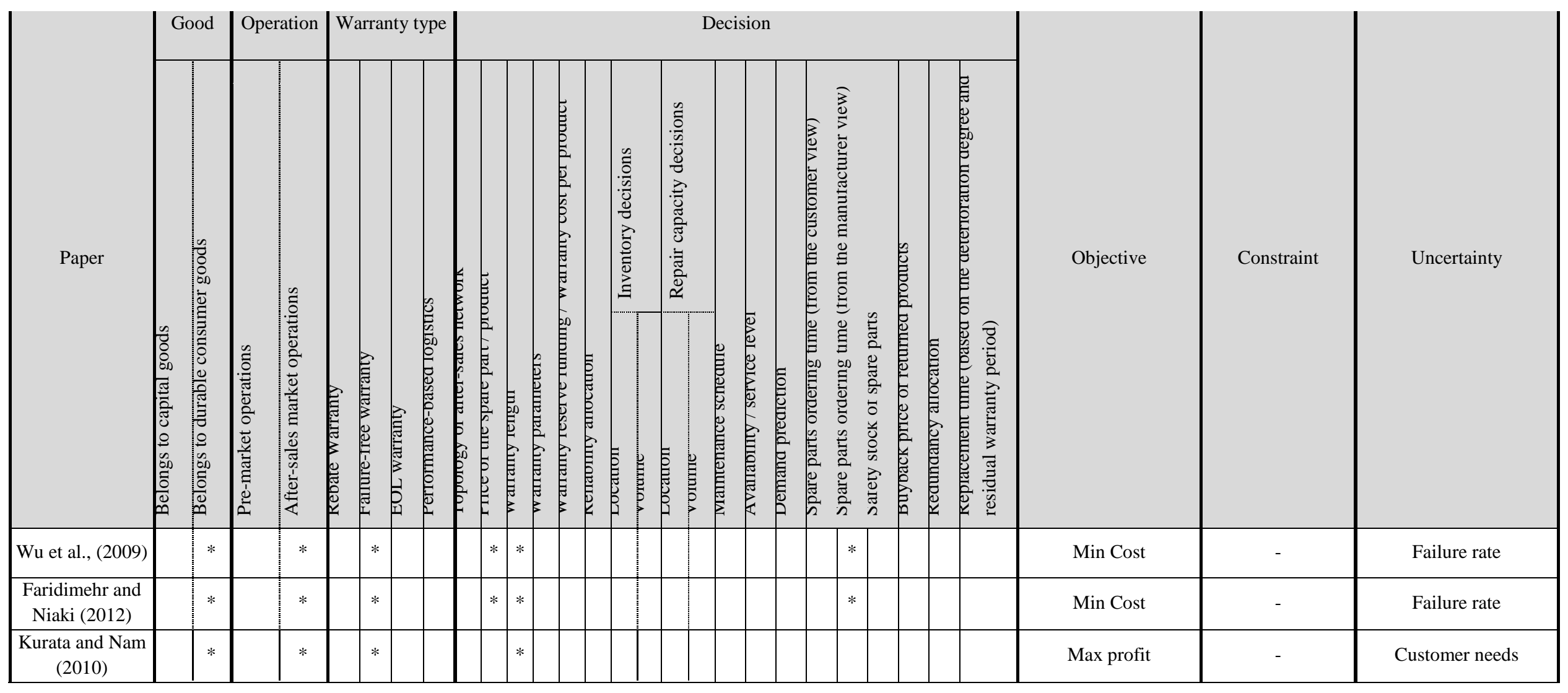




\begin{tabular}{|c|c|}
\hline Variables & \\
\hline$r l_{1}$ & Local reliability of the retailer \\
\hline$r l_{2}$ & Local reliability of the manufacturer \\
\hline$r l_{3}$ & Local reliability of the suppliers \\
\hline$s l_{p}$ & Service level in the pre-market \\
\hline$s l_{a}$ & Service level in the after-sales market \\
\hline$w$ & Warranty time \\
\hline$x$ & Product order quantity by the retailer \\
\hline$\Delta x$ & Extra production volume in the manufacturer \\
\hline$\Delta \dot{x}_{i}$ & Extra production volume in Supplier $i$ for the forward SC $(i=1,2,3, \ldots, r)$ \\
\hline$x_{i}$ & Order quantity of Component $i$ by the retailer $(i=1,2,3, \ldots, r)$ \\
\hline$\Delta x_{i}^{\prime \prime}$ & Extra production volume in Supplier $i$ for the after-sales SC $(i=1,2,3, \ldots, r)$ \\
\hline$y_{r l 1^{i}}$ & $\begin{array}{l}\text { Binary variable equal to } 1 \text { if the local reliability } r l 1^{i} \text { is selected from set } R L 1 \text { for the retailer; } 0 \text { otherwise } \\
\left(\forall r l 1^{i} \in R L 1\right)\end{array}$ \\
\hline$y_{r l 2^{i}}$ & $\begin{array}{l}\text { Binary variable equal to } 1 \text { if the local reliability } r l 2^{i} \text { is selected from set } R L 2 \text { for the manufacturer; } 0 \\
\text { otherwise }\left(\forall r l 2^{i} \in R L 2\right)\end{array}$ \\
\hline$y_{r l 3^{i}}$ & $\begin{array}{l}\text { Binary variable equal to } 1 \text { if the local reliability } r l 3^{i} \text { is selected from set } R L 3 \text { for the suppliers; } 0 \text { otherwise } \\
\left(\forall r l 3^{i} \in R L 3\right)\end{array}$ \\
\hline$z_{w^{i}}$ & Binary variables equal to 1 if the warranty length $w^{i}$ is selected from set $W\left(\forall w^{i} \in W\right)$ \\
\hline Parameters & \\
\hline$\grave{\Pi}$ & Profit of the company \\
\hline$\Pi$ & Total cost of the retailer \\
\hline$T$ & Length of the sale period \\
\hline$p$ & Price of the product in the pre-market \\
\hline$\widehat{D}\left(p, s l_{p}, s l_{a}, w\right)$ & Stochastic product demand function in the pre-market \\
\hline$D\left(p, s l_{p}, s l_{a}, w\right)$ & Expected product demand in the pre-market \\
\hline$\varepsilon$ & Random part of the pre-market demand \\
\hline$G()$. & Cumulative distribution function of $\varepsilon$ \\
\hline$h^{+}$ & Unit holding cost of extra product inventory at the end of the sale period in the retailer \\
\hline$h^{-}$ & Unit shortage cost of lost product sale at the end of the sale period in the retailer \\
\hline$r$ & Number of critical components in the product \\
\hline$\dot{G}()$. & Cumulative distribution function of wastage ratio in the manufacturer \\
\hline$\beta$ & Maximum wastage ratio in the manufacturer of the sample problem \\
\hline$\mu_{i}$ & Average number of failures in the time unit in Supplier $i(i=1,2,3, \ldots, r)$ \\
\hline$\gamma_{i}$ & Defective component ratio in the out-of-control state of Supplier $i(i=1,2,3, \ldots, r)$ \\
\hline$a_{1 i}$ & Unit procurement cost of material in Supplier $i(i=1,2, \ldots, r)$ \\
\hline$a_{2 i}$ & Unit production cost of Component $i$ in Supplier $i(i=1,2, \ldots, r)$ \\
\hline$h_{1 i}$ & Unit inventory holding cost for a time unit in Supplier $i(i=1,2, \ldots, r)$ \\
\hline$b_{1 i}$ & Unit transportation cost of product from Supplier $i$ to the manufacturer $(i=1,2, \ldots, r)$ \\
\hline$b_{2}$ & Unit product manufacturing cost in the manufacturer \\
\hline$h_{2}$ & Unit inventory holding cost for a time unit in the manufacturer \\
\hline$c_{1}$ & Unit transportation cost of product from the manufacturer to the retailer \\
\hline$c_{2}$ & Unit handling cost of product in the retailer \\
\hline$c_{3 i}$ & Unit transportation cost of Component $i$ from Supplier $i$ to the retailer $(i=1,2, \ldots, r)$ \\
\hline$P R_{1 i}$ & Production rate of Supplier $i(i=1,2, \ldots, r)$ \\
\hline$P R_{2}$ & Production rate of the manufacturer \\
\hline$\lambda_{i}$ & Reliability parameter of Component $i(i=1,2,3, \ldots, r)$ \\
\hline$f_{i}()$. & Density function of failure time of Component $i(i=1,2,3, \ldots, r)$ \\
\hline
\end{tabular}




$\begin{array}{|ll|}F_{i}(.) & \text { Cumulative distribution function of failure time of Component } i(i=1,2,3, \ldots, r) \\ F_{i}^{(m)}(.) & \text { Cumulative distribution function of total time to the } m^{\text {th }} \text { failure of Component } i(i=1,2,3, \ldots, r) \\ n_{i} & \text { Number of first failures of Component } i \text { that are repairable }(i=1,2,3, \ldots, r) \\ c n_{i} & \text { Unit repair cost of Component } i(i=1,2,3, \ldots, r) \\ c r & \text { Average repair cost of the product unit; } \\ N u m_{i} & \text { Random number of Component } i \text { substitutions for a product unit in warranty time }(i=1,2,3, \ldots, r) \\ E_{i} & \text { Average number of Component } i \text { substitutions for a product unit in warranty time }(i=1,2,3, \ldots, r) \\ \sigma_{i}^{2} & \text { Variance of number of Component } i \text { substitutions for a product unit in warranty time }(i=1,2,3, \ldots, r) \\ D_{i} & \text { Average number of Component } i \text { substitutions in warranty time in the after-sales market }(i=1,2,3, \ldots, r) \\ k_{1} & \text { Number of sale periods inside the warranty time } \\ T & \text { Biggest time period inside the sale period in which it is logical to assume that the product demand occurs at } \\ k_{2} & \text { its beginning } \\ D_{i j} & \text { Number of } T \text { s inside the sale period } \\ R L 1 & \text { Required quantity of Component } i \text { to repair product lot } x / k_{2} \text { in the } j^{\text {th }} \text { period } T \text { of its selling time; } \\ R L 2 & \text { Set of scenarios for the local reliability of the retailer } R L 1=\left\{r l 1^{1}, r l 1^{2}, \ldots, r l 1^{|R L 1|}\right\} \\ R L 3 & \text { Set of scenarios for the local reliability of the manufacturer } R L 2=\left\{r l 2^{1}, r l 2^{2}, \ldots,\left.r l\right|^{|R L 2|}\right\} \\ W & \text { Set of scenarios for the local reliability of the suppliers } R L 3=\left\{r l 3^{1}, r l 3^{2}, \ldots, r l 3^{|R L 3|}\right\} \\ & \text { Set of warranty length } W=\left\{w^{1}, w^{2}, \ldots, w^{|W|}\right\} \\ & \end{array}$


Table 3. Best warranty strategy in different price intervals.

\begin{tabular}{|c|c|c|c|c|}
\hline Price interval & $p<\$ 11.25$ & $\$ 11.25<p \leq \$ 11.82$ & $\$ 11.82<p \leq \$ 12.37$ & $\$ 12.37<p$ \\
\hline Best warranty & $w^{*}=6(\mathrm{mo})$. & $w^{*}=12(\mathrm{mo})$. & $w^{*}=18(\mathrm{mo})$. & $w^{*}=24(\mathrm{mo})$. \\
\hline
\end{tabular}


Table 4

Table 4. Best warranty strategy in the price-sensitive market.

\begin{tabular}{|c|c|c|c|c|}
\hline Price interval & $p<\$ 10.90$ & $\$ 10.90<p \leq \$ 11.20$ & $\$ 11.20<p \leq \$ 11.55$ & $\$ 11.55<p$ \\
\hline Best warranty & $w^{*}=6(\mathrm{mo})$ & $w^{*}=12(\mathrm{mo})$. & $w^{*}=18(\mathrm{mo})$ & $w^{*}=24\left(m o s_{0}\right)$ \\
\hline
\end{tabular}




\section{Table 5}

Table 5. Best warranty strategy in the warranty-sensitive market.

\begin{tabular}{|l|c|c|c|c|}
\hline Price interval & $p<\$ 11.17$ & $\$ 11.17<p \leq \$ 11.95$ & $\$ 11.95<p \leq \$ 12.75$ & $\$ 12.75<p$ \\
\hline Best warranty & $w^{*}=6(\mathrm{mo})$. & $w^{*}=12(\mathrm{mo})$. & $w^{*}=18(\mathrm{mo})$. & $w^{*}=24(\mathrm{mo})$. \\
\hline
\end{tabular}

